OPEN ACCESS

Edited by:

Rongtuan Lin,

McGill University, Canada

Reviewed by:

Sampsa Matikainen,

University of Helsinki, Finland

Chunfu Zheng,

Fujian Medical University, China

*Correspondence:

Wen-Zhe Ho

wenzheho@temple.edu

Wei Hou

houwei@whu.edu.cn

${ }^{\text {t}}$ These authors have contributed equally to this work

Specialty section: This article was submitted to Viral Immunology,

a section of the journal

Frontiers in Immunology

Received: 25 August 2020 Accepted: 16 December 2020

Published: 04 February 2021

Citation:

Shao D-D, Meng F-Z, Liu Y, Xu X-Q, Wang $X$, Hu W-H, Hou W and Ho W-Z (2021) Poly(dA:dT) Suppresses HSV-2 Infection of Human Cervical Epithelial

Cells Through R/G-I Activation.

Front. Immunol. 11:598884.

doi: 10.3389/fimmu.2020.598884

\section{Poly(dA:dT) Suppresses HSV-2 Infection of Human Cervical Epithelial Cells Through RIG-I Activation}

\author{
Dan-Dan Shao ${ }^{1 \dagger}$, Feng-Zhen Meng ${ }^{1 \dagger}$, Yu Liu ${ }^{2}$, Xi-Qiu Xu ${ }^{1}$, Xu Wang ${ }^{2}$, Wen-Hui Hu${ }^{2}$, \\ Wei Hou ${ }^{1 *}$ and Wen-Zhe $\mathrm{Ho}^{2 *}$ \\ ${ }^{1}$ School of Basic Medical Sciences, Wuhan University, Wuhan, China, ${ }^{2}$ Department of Pathology and Laboratory Medicine, \\ Lewis Katz School of Medicine, Temple University, Philadelphia, PA, United States
}

Epithelial cells of the female reproductive tract (FRT) participate in the initial innate immunity against viral infections. Poly $(d A: d T)$ is a synthetic analog of $B$ form doublestranded (ds) DNA which can activate the interferon (IFN) signaling pathway-mediated antiviral immunity through DNA-dependent RNA Polymerase III. Here we investigated whether poly(dA:dT) could inhibit herpes simplex virus type 2 (HSV-2) infection of human cervical epithelial cells (End1/E6E7). We demonstrated that poly(dA:dT) treatment of End1/E6E7 cells could significantly inhibit HSV-2 infection. Mechanistically, poly(dA:dT) treatment of the cells induced the expression of the intracellular IFNs and the multiple antiviral IFN-stimulated genes (ISGs), including IFN-stimulated gene 15 (ISG15), IFNstimulated gene 56 (ISG56), 2'-5'-oligoadenylate synthetase 1 (OAS1), 2'-5'oligoadenylate synthetase 2 (OAS2), myxovirus resistance protein A (MxA), myxovirus resistance protein $\mathrm{B}(\mathrm{MxB})$, virus inhibitory protein, endoplasmic reticulum-associated, IFN-inducible (Viperin), and guanylate binding protein 5 (GBP5). Further investigation showed that the activation of RIG-I was largely responsible for poly(dA:dT)-mediated HSV-2 inhibition and IFN/ISGs induction in the cervical epithelial cells, as RIG-I knockout abolished the poly(dA:dT) actions. These observations demonstrate the importance for design and development of AT-rich dsDNA-based intervention strategies to control HSV2 mucosal transmission in FRT.

Keywords: herpes simplex virus type 2, human cervical epithelial cells, poly(dA:dT), interferon, interferon-stimulated gene, retinoic acid-inducible gene-I

\section{INTRODUCTION}

Herpes simplex virus type 2 (HSV-2) is the leading cause of genital herpes and the most commonly sexual transmitted virus. It is estimated that 417 million people aged 15-49 (11\%) worldwide are infected with HSV-2 infection in 2012 (1). Importantly, the epidemiological and biological studies have shown a strong association between human immunodeficiency virus 1 (HIV-1) and HSV-2 infection. HSV-2 infection increases the risk of HIV-1 acquisition by approximately three-fold (2) and facilitates transmissibility of HIV-1 up to five-fold through genital ulcers (3). In turn, HIV-1 
TABLE 1 | Primer sets for real-time PCR.

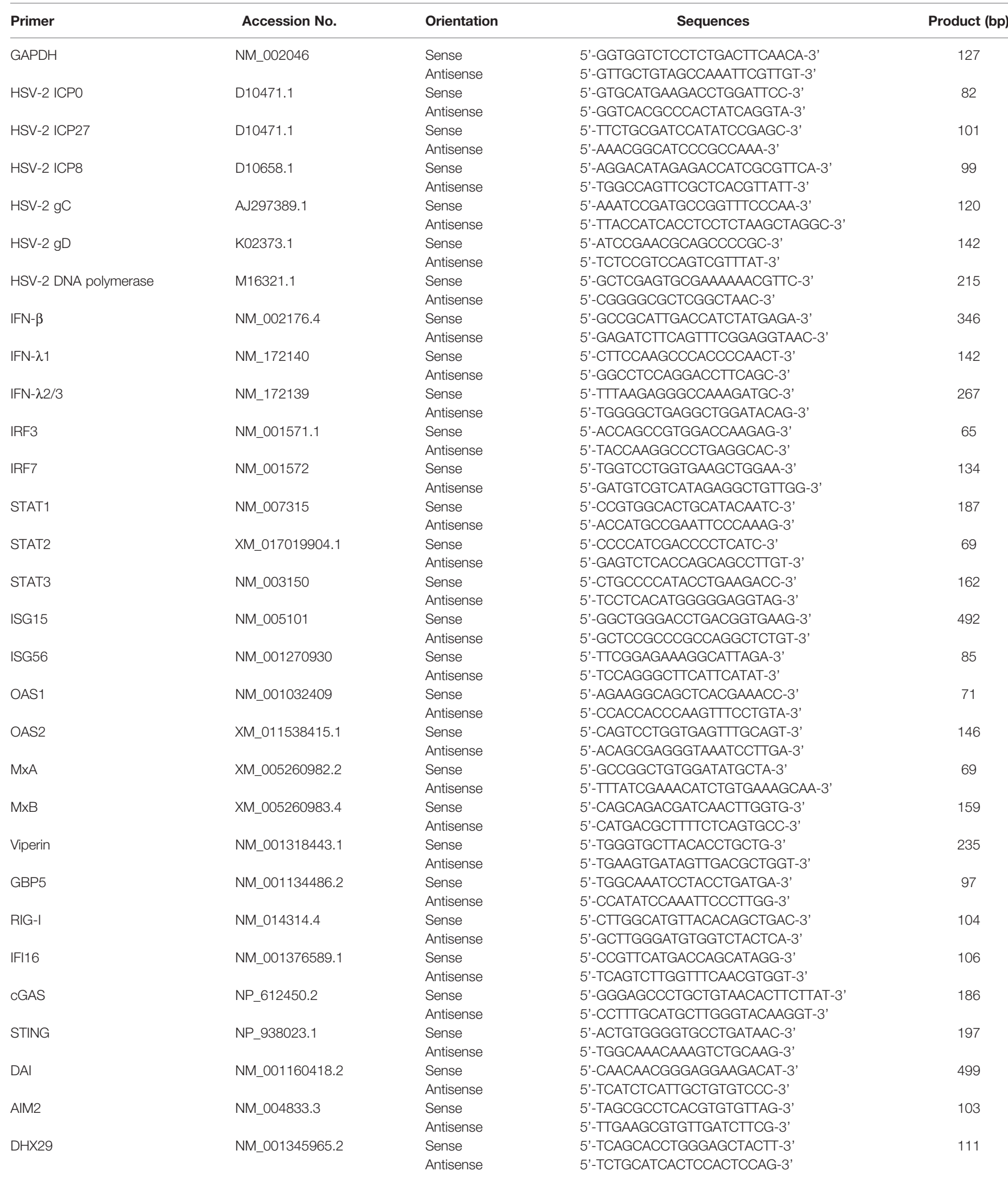




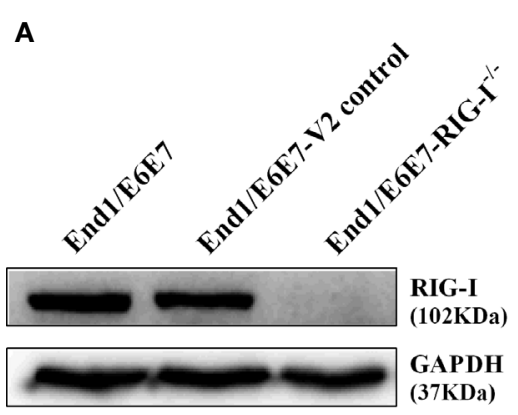

C
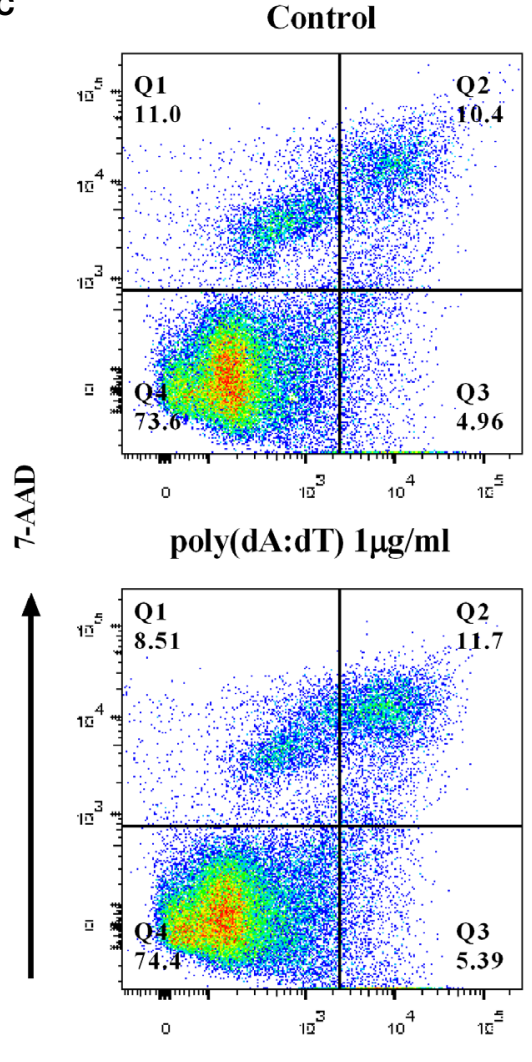
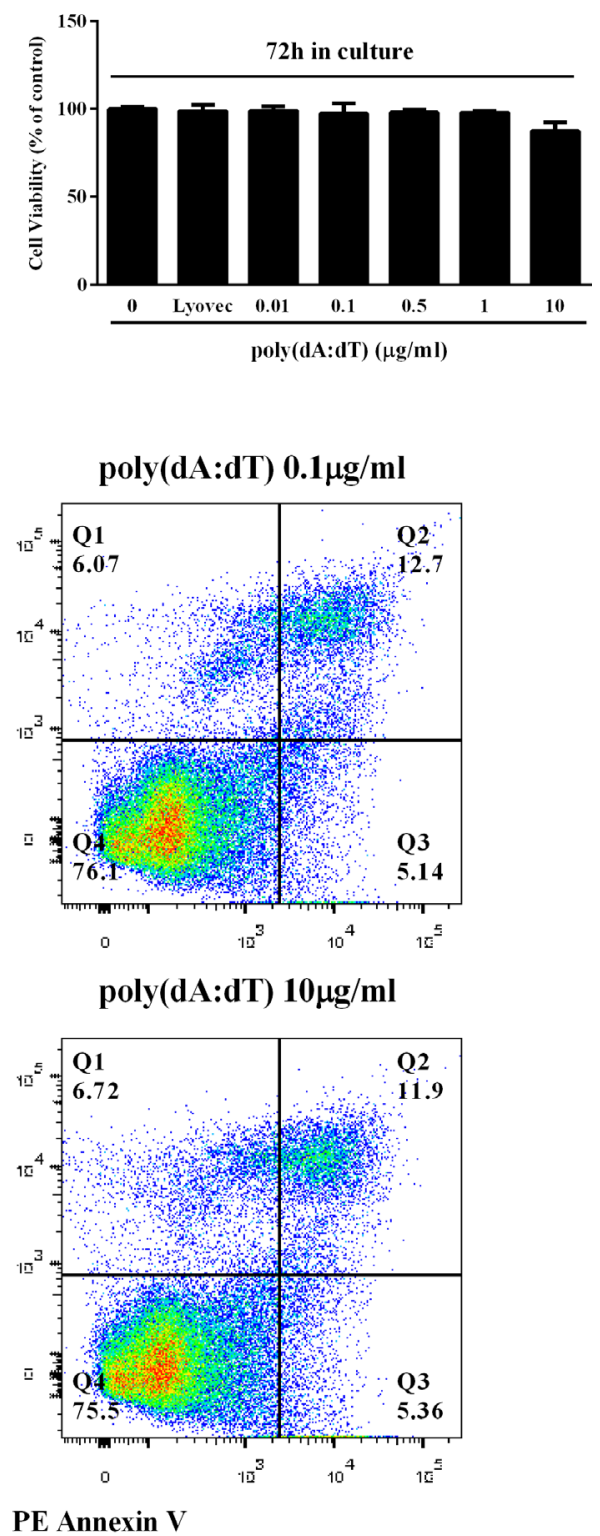

FIGURE 1 | Effect of poly(dA:dT) on End1/E6E7 cells. (A) Cell lysates of End1/E6E7 cells, End1/E6E7 V2 control cells and RIG-I knockout End1/E6E7 cells were subjected to Western blot assay for RIG-I expression and GAPDH was used as a protein loading control. (B, C) End1/E6E7 cells were treated with poly(dA:dT) at the indicated concentrations, and cell viability was assessed by MTT assay (B) and annexin V/7-AAD assay (C) 72h post poly(dA:dT) treatment.

infection enhances HSV-2 shedding frequency and quantity (4, 5), people with HIV-1-related immunosuppression can have severe HSV-2 diseases $(6,7)$.

Epithelial cells in the female reproductive tract (FRT) are the first barrier to pathogen invasion. At cellular level, epithelial cells constitute a unique microenvironment and participate in FRT innate immunity against viral infections, including $\operatorname{HSV}-2(8,9)$. HSV-2 primarily infects genital epithelium and replicates within the vaginal keratinocytes (10). Human cervical epithelial cells have been extensively used to study FRT-mediated immunity against viral infections (11-14). Studies have shown that these cells could be immunologically activated and produced the multiple antiviral factors against HSV-2 (12) and HIV-1 (15). As the outmost layer cells in FRT, human cervical epithelial cells are the first to contact with invading microbes. Thus, understanding the processes and mechanisms of these cellsmediated innate immunity against viral infections is of importance and significance. 
A

\section{Intracellular}

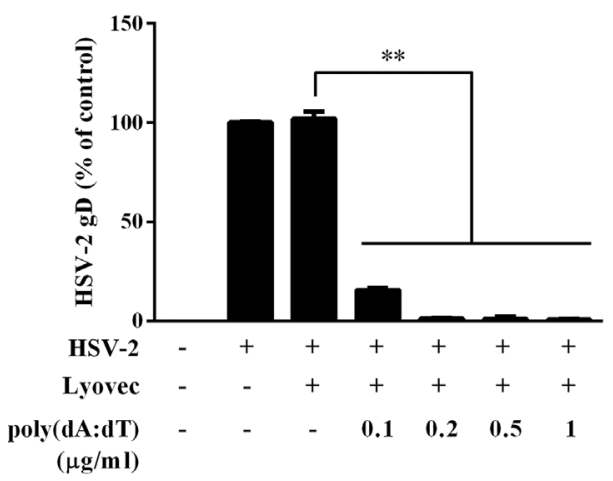

C

Extracellular

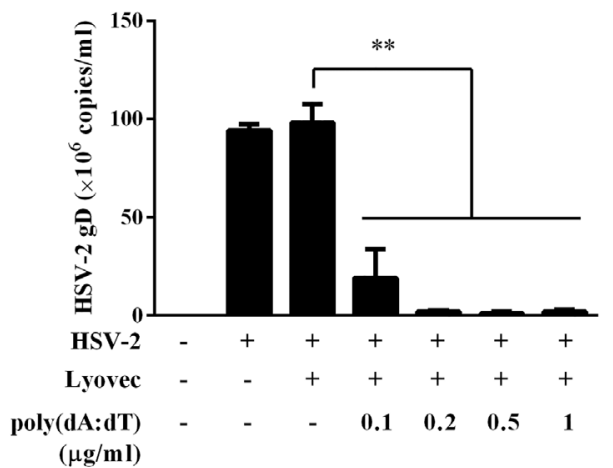

E
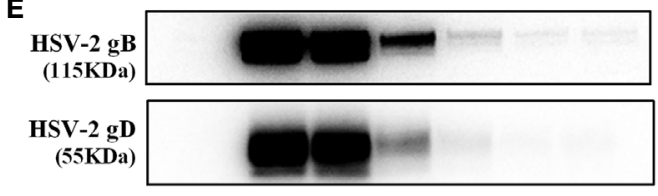

GAPDH

(37KDa)

HSV-2

Lyovec

poly $($ dA:dT $)$

$(\mu \mathrm{g} / \mathrm{mI})$
B

Intracellular

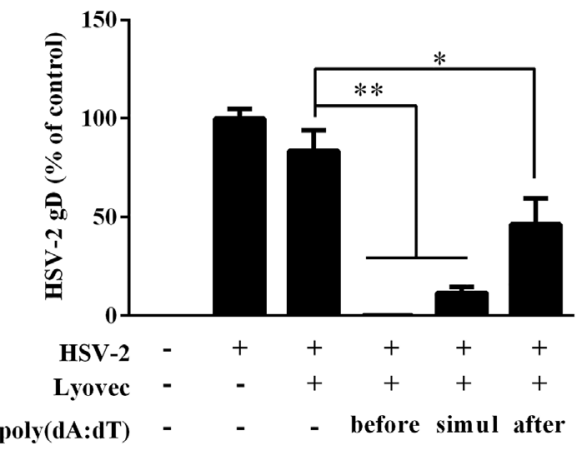

D

Extracellular

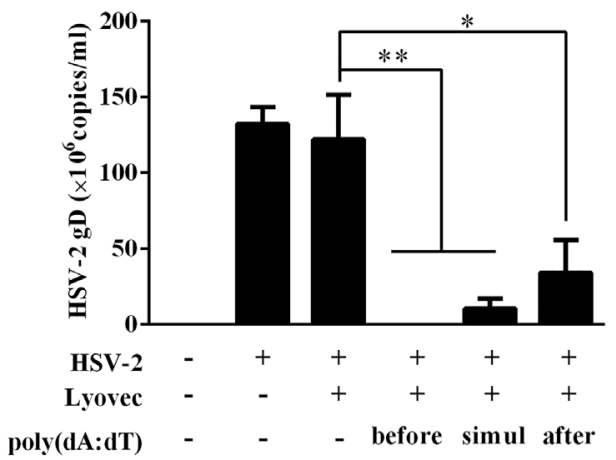

F

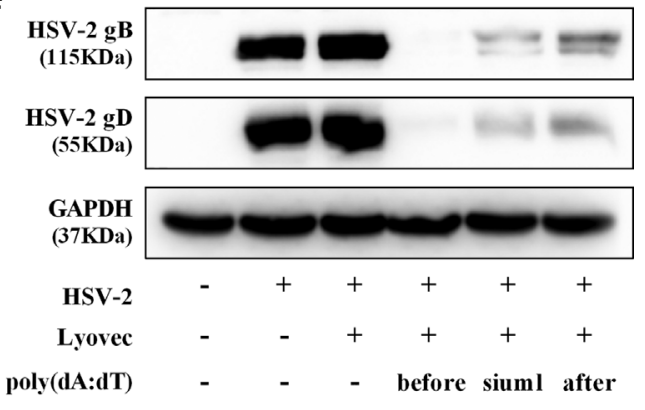

FIGURE 2 | Poly(dA:dT) inhibits HSV-2 infection. (A, C, E) End1/E6E7 cells were pretreated with poly(dA:dT) at indicated concentrations for 24h prior to HSV-2 $(\mathrm{MOI}=0.001)$ infection. Forty-eight hours after HSV-2 infection, (A) intracellular DNA, (C) extracellular DNA, and (E) total cellular proteins were collected and subjected to the real-time PCR or Western blot for HSV-2 gene expression. (B, D, F) End1/E6E7 cells were treated with either poly $(\mathrm{dA}: \mathrm{dT})(0.5 \mu \mathrm{g} / \mathrm{ml})$ for $24 \mathrm{~h}$ prior to HSV-2 (MOI=0.001) infection (before) or poly(dA:dT) and infected with HSV-2 simultaneously (simul) or infected with HSV-2 for $2 \mathrm{~h}$ prior to poly(dA:dT) treatment (after). At 48h post HSV-2 infection, (B) intracellular DNA, (D) extracellular DNA, and (F) total cellular proteins were collected and analyzed by the real-time PCR or Western blot for HSV-2 gene expression. Data shown are the mean \pm SD of three independent experiments. Asterisks indicate statistically significant differences. $\left({ }^{\star} P<0.05,{ }^{*} P<0.01\right)$.

DNA-dependent RNA polymerase III (RNA Pol III) is involved in DNA-mediated innate immunity response by converting AT-rich DNA into a RNA intermediate which can be recognized by RIG-I, resulting in the activation of interferon (IFN) signaling pathway. Poly (dA:dT) is a synthetic analog of B form double stranded DNA (dsDNA) can be sensed by the RNA Pol III and then recognized by cytosolic RNA sensor RIG-I, eliciting an intracellular immune response to control virus replication (16-18). IFN regulatory factor 3 (IRF3) and IRF7 are the crucial transcription factors involved in RIG-I signaling 

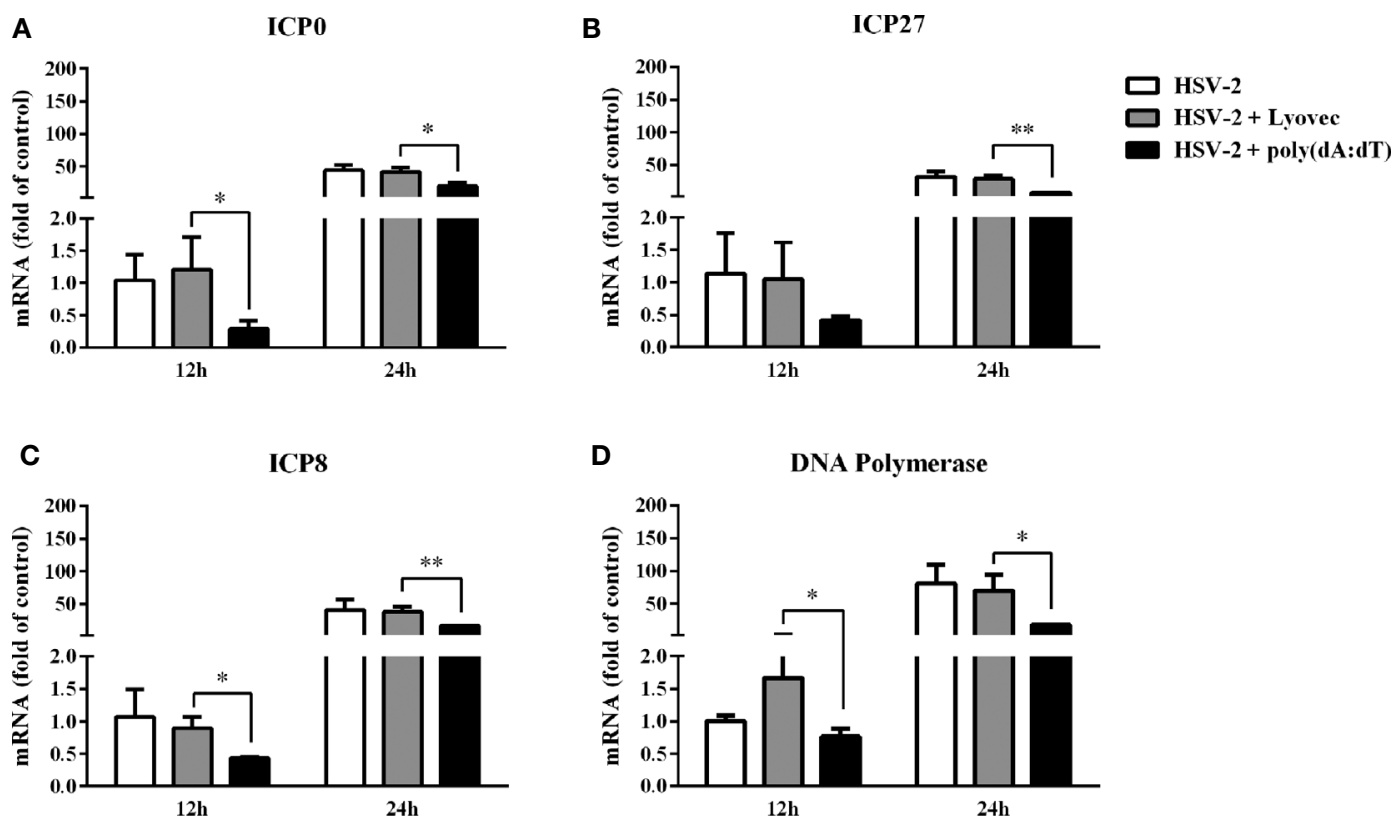

DNA Polymerase
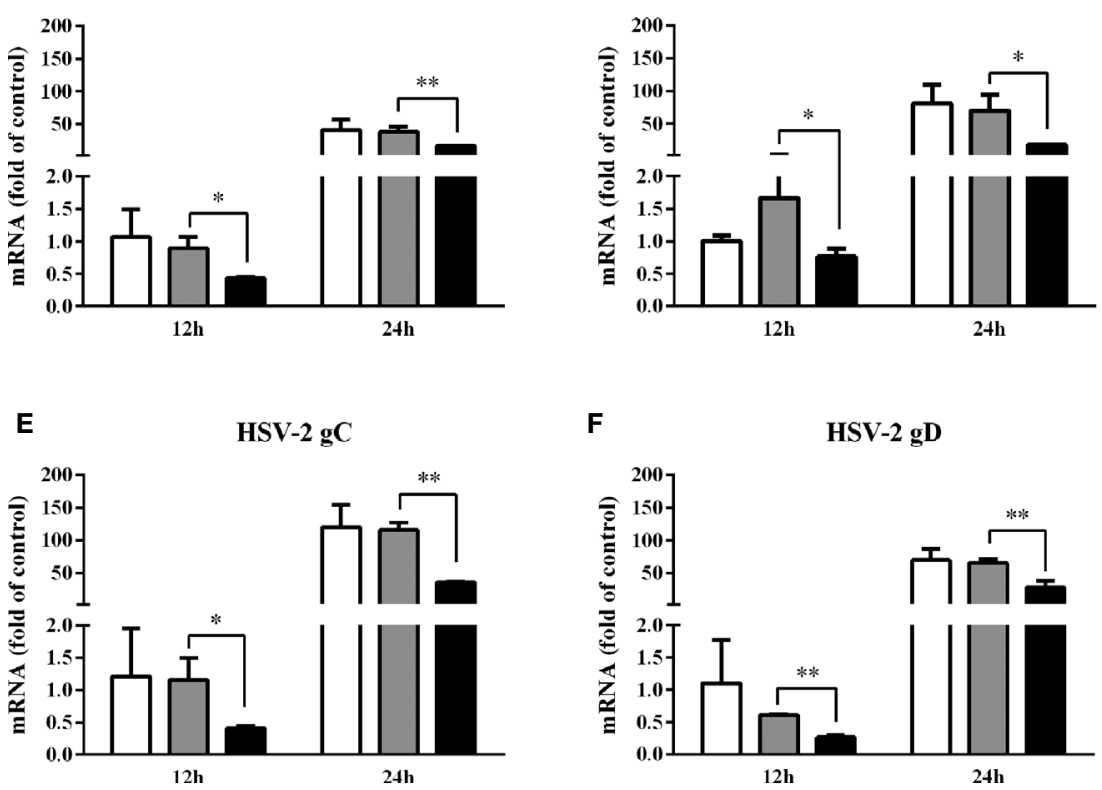

FIGURE 3 | Effect of poly(dA:dT) on HSV-2 gene expression. End1/E6E7 cells were transfected with or without poly(dA:dT) $(0.5 \mu \mathrm{g} / \mathrm{ml})$ at indicated concentrations for $24 \mathrm{~h}$ prior to HSV-2 infection ( $\mathrm{MOI}=0.001)$. Cellular RNAs were collected from the virus-infected cells at 12 or $24 \mathrm{~h}$ post infection and subjected to the real-time PCR for HSV-2 immediate early genes (A, B), early genes (C, D) and late genes (E, F) expression. The results were measured as HSV-2 gene levels relative (\%) to control (without treatment, which is defined as $100 \%$ ). Data are shown as mean \pm SD of three independent experiments. Asterisks indicate statistically significant differences $\left({ }^{\star} P<0.05,{ }^{\star \star} P<0.01\right)$.

pathway (19). It has been reported that the association of RIG-I with pre-genomic RNA can induce type III IFN and inhibit hepatitis B virus (20). Type III IFN, also known as IFN lambda (IFN- $\lambda$ ), can induce expression of ISGs and exert antiviral properties similar to type I IFNs (21).

Studies have shown that activation of IFN-dependent innate immune defense through RIG-I signaling pathway is vital in antiviral response of epithelial cells (22-24). However, we know little about whether poly(dA:dT) has the ability to activate the intracellular antiviral immunity of human cervical epithelial cells, an essential component of the mucosal defense mechanisms in the FRT. In this study, we examined whether poly $(\mathrm{dA}: \mathrm{dT})$ has the ability to induce the intracellular antiviral factors against HSV-2 infection of human cervical epithelial cells. We also explored the cellular and molecular mechanisms underlying poly(dA:dT)-mediated IFN/ISG induction and HSV-2 inhibition in these cells.

\section{MATERIALS AND METHODS}

\section{Cell Lines and Virus}

End1/E6E7 cell line was established from normal human endocervical epithelia immortalized by expression of human papillomavirus 16/E6E7. End1/E6E7 cells have exactly the same cytokeratin and involucrin patterns as primary End1 cells and the morphological and immunocytochemical characteristics of the End1/E6E7 cells closely resembled those of origin and primary cultures. Therefore, End1/E6E7 cells provide the basis for valid reproducible in vitro models for studies on 
A

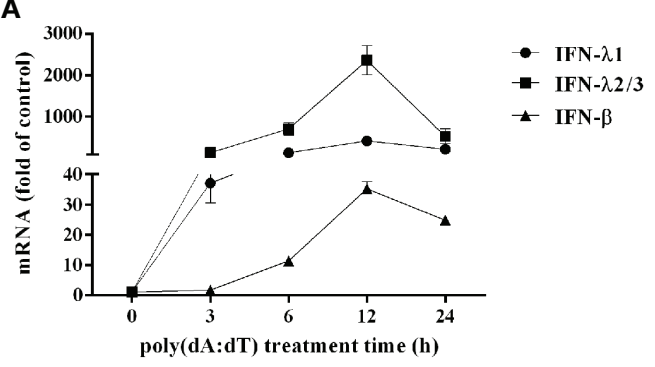

C

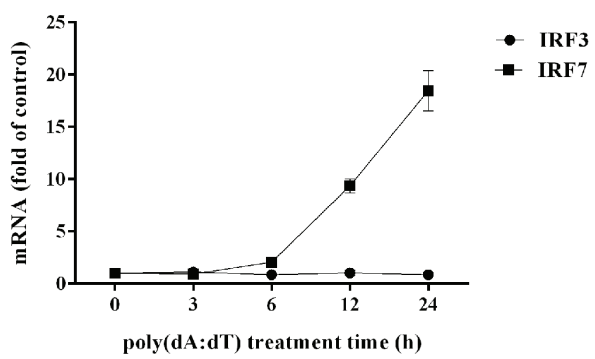

B

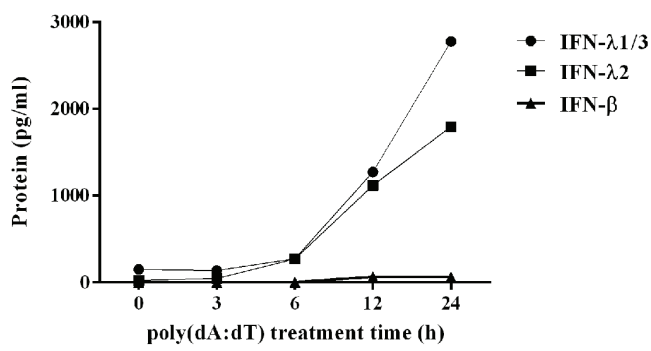

D

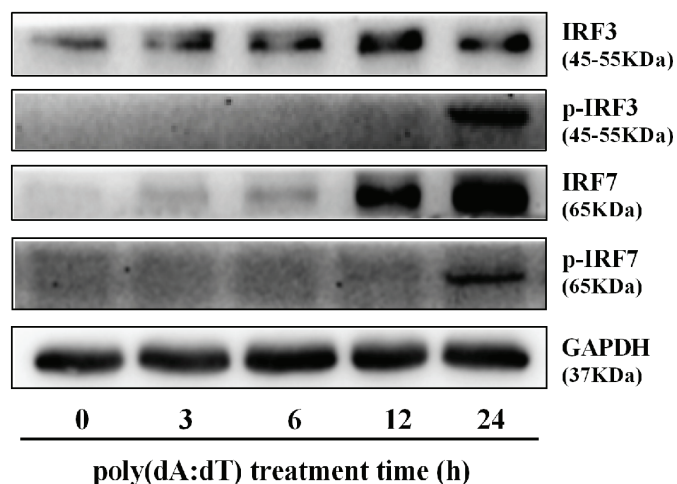

FIGURE 4 | Effect of poly(dA:dT) on IFNs and IRFs expression. End1/E6E7 cells were transfected with or without poly(dA:dT) $(0.5 \mu \mathrm{g} / \mathrm{ml})$ for the indicated times. $(\mathbf{A}, \mathbf{C})$ Total cellular RNAs were extracted and subjected to the real-time PCR for IFN- $\beta$, IFN- $\lambda 1$, IFN- $\lambda 2 / 3$, and IRF3, IRF7 expression. (B) The cell-free supernatant was subjected to ELISA assay to determine IFN- $\beta$, IFN- $\lambda 1 / 3$, and IFN- $\lambda 2$ protein levels. (D) Total cellular proteins were collected and subjected to Western blot with the antibodies against IRF3, IRF7, p-IRF3, p-IRF7, and GAPDH. Data are shown as mean \pm SD of three independent experiments.

cervicovaginal physiology and infections and for testing pharmacological agents for intravaginal application (25). In addition, End1/E6E7 cell line has been broadly used as an in vitro model of human female reproductive tract $(13,26,27)$. End1/E6E7 cells were cultured in keratinocyte growth medium (Gibco, USA) supplemented with the provided recombinant epidermal growth factor $(0.1 \mathrm{ng} / \mathrm{ml})$ and bovine pituitary extract $(50 \mu \mathrm{g} / \mathrm{ml})$. African green monkey kidney epithelial cells (Vero) and 293T cells were cultured in Dulbecco's modified Eagle's culture medium (DMEM, Gibco) supplemented with $10 \%$ fetal bovine serum (FBS, Gibco) at $37^{\circ} \mathrm{C}$ in a humidified atmosphere of $5 \% \mathrm{CO}_{2}$. HSV-2 G strain was provided by Dr. Qinxue Hu (State Key Laboratory of Virology, Wuhan Institute of Virology, Chinese Academy of Sciences, China). The HSV-2 G strain was propagated at a low multiplicity of infection $(\mathrm{MOI}=$ 0.001 ) in Vero cells.

\section{Plasmids and Reagents}

LentiCRISPRv2-puro, psPAX2, and pMD2.G plasmids were provided by Dr. Jian Huang (Department of Pathology and Laboratory Medicine, Temple University, USA). PE Annexin V Apoptosis Detection Kit I was purchased from BD (Pharmingen, USA). Poly(dA:dT), LyoVec, and puromycin were purchased from InvivoGen (San Diego, CA, USA). Lipofectamine 3000
Reagent was purchased from Thermo Fisher Scientific (Carlsbad, CA, USA). Antibodies against RIG-I, DNA sensors, ISGs, signal transducers and activators of transcription (STATs), and IRFs were purchased from Cell Signaling Technology (Danvers, MA, USA). Antibodies against HSV-1+HSV-2 gD, HSV - 1+HSV-2 gB were purchased from Abcam (Cambridge, UK). Antibody to GAPDH was purchased from Proteintech (Chicago, USA).

\section{Cell Viability Assay}

The cytotoxic effect of poly $(\mathrm{dA}: \mathrm{dT})$ was evaluated by the MTT assay based on the manufacturer's instruction. End1/E6E7 cells were seeded in 96-well plate $\left(1 \times 10^{4}\right.$ cells/well $)$ treated with different concentrations of poly(dA:dT) for $72 \mathrm{~h}$. Cells were then incubated with MTT working solution $(0.5 \mathrm{mg} / \mathrm{ml})$ for $4 \mathrm{~h}$ at $37^{\circ} \mathrm{C}$ in darkness. The formation of soluble formazan from MTT was measured by spectrophotometric determination of absorption at 490nm using a 96-well plate reader (SpectraMax i3, Molecular Devices, Sunnyvale, CA, USA).

\section{Flow Cytometry Analysis of Apoptosis}

We used Annexin V/7-AAD assay to measure the apoptosis effect of poly (dA:dT) on End1/E6E7 cells. Cells were seeded in 24 -well plate $\left(2 \times 10^{5}\right.$ cells/well $)$ and treated with different concentrations of poly $(\mathrm{dA}: \mathrm{dT})$ for $72 \mathrm{~h}$. Cells were washed 


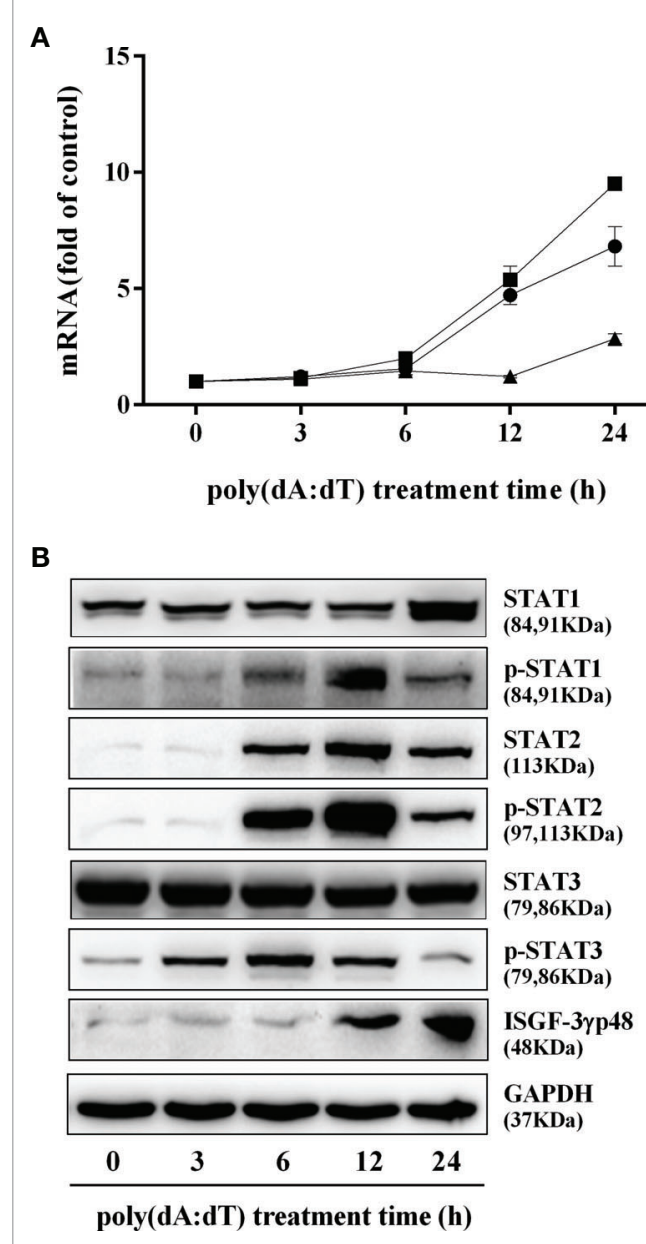

FIGURE 5 | Effect of poly(dA:dT) on JAK/STAT signaling pathway. End1/ E6E7 cells were transfected with or without poly $(\mathrm{dA}: \mathrm{dT})(0.5 \mu \mathrm{g} / \mathrm{ml})$ for the indicated times. (A) Total cellular RNAs were extracted and subjected to the real-time PCR for STAT1, STAT2, and STAT3 expression. (B) Total cellular proteins were collected and subjected to Western blot with the antibodies against STAT1, STAT2, STAT3, p-STAT1, p-STAT2, p-STAT3, ISGF-3yp48, and $\mathrm{GAPDH}$. Data are shown as mean $\pm \mathrm{SD}$ of three independent experiments.

twice with cold phosphate-buffered saline (PBS) and then resuspended in $1 \times$ binding buffer at a concentration of $1 \times 10^{5}$ cells/ml. Annexin V-PE $(2.5 \mu \mathrm{l})$ and 7 -AAD $(5 \mu \mathrm{l})$ were added and then incubated for $15 \mathrm{~min}$ at room temperature without light, finally analyzed by FCM (FACScan, Becton Dickinson, San Jose, CA).

\section{RNA Extraction and Real-Time PCR}

Total cellular RNAs from the cells were extracted using TRIReagent $^{\circledR}$ (Molecular Research Center, Cincinnati, OH) according to the manufacturer's instruction. Total RNAs were subjected to reverse transcription reaction using the random primer, dNTPs, M-MLV reverse transcriptase and RNase inhibitor (Promega Co., Madison, WI) to generate complementary DNA (cDNA). cDNA was then used as a template for real-time PCR which was performed with IQ SYBR Green supermix (Bio-Rad Laboratories, Hercules, CA). The level of GAPDH mRNA was used as an endogenous reference to normalize the quantities of target mRNAs. The sequences of oligonucleotide primers are shown in Table $\mathbf{1 .}$

\section{In Vitro Antiviral Assay}

End1/E6E7 cells were pretreated with poly(dA:dT) for $24 \mathrm{~h}$ and infected with HSV-2 (MOI $=0.001)$ for $2 \mathrm{~h}$. The cells were then washed to remove unattached viruses and subsequently cultured for 48h. HSV-2 genome DNAs from HSV-2-infected cells and culture supernatant were extracted with DNA lysis buffer as previously described (12) and subjected to the real-time PCR. HSV-2 gD standards with known copy numbers were used to quantify HSV-2 gD copies in the culture supernatant. Total proteins were extracted from End1/E6E7 cells and subjected to the Western blot. In addition, the antiviral effect of poly(dA:dT) under different treatment conditions (before, simultaneously and after HSV-2 infection) was evaluated. Briefly, End1/E6E7 cells were pretreated with poly $(\mathrm{dA}: \mathrm{dT})(0.5 \mu \mathrm{g} / \mathrm{ml})$ for $24 \mathrm{~h}$, then infected with HSV-2 (before); End1/E6E7 cells were simultaneously (simul) treated with poly $(\mathrm{dA}: \mathrm{dT})$ and infected with HSV-2; End1/E6E7 cells were first infected with HSV-2 for $2 \mathrm{~h}$, then washed and treated with poly(dA:dT) (after). At $48 \mathrm{~h}$ post infection, both HSV-2 genomic DNA and total proteins were extracted from End1/E6E7 cells and subjected to the realtime PCR or Western blot assay.

\section{CRISPR Cas9}

We used the CRISPR Cas9 system to abrogate RIG-I expression in End1/E6E7 cells. Briefly, we designed gRNA (5'GGGTCTTCCGGGATATAATCC-3') targeting the conserved sites in human RIG-I genomic sequences based on CCTop (https://crispr.cos.uni-heidelberg.de/). The gRNA was then subcloned into the lentiCRISPRv2 plasmid to obtain the lentiCRISPRv2-gRNA clone that expressed both Cas9 and gRNA according to the publications' instruction $(28,29)$. Then lentiCRISPRv2-gRNA plasmid and two packaging plasmids, psPAX2 and pMD2.G, were co-transfected into 293T cells to obtain lentivirus. LentiCRISPRv2 was used as an empty vector control. Three days after the lentivirus infection, End1/E6E7 cells were cultured with puromycin $(0.5 \mu \mathrm{g} / \mathrm{ml})$ containing medium for 14 days. Total cellular proteins were then collected and subjected to Western blot for RIG-I protein expression.

\section{Western Blot}

Total cell lysates were prepared with the cell extraction buffer (Invitrogen, Shanghai, China) with $1 \%$ protease inhibitor cocktail (Sigma, MO) and 1\% phosphatase inhibitor mixture (Applygen, Beijing, China). The total proteins were quantified by a BCA protein assay kit (Beyotime Institute of Biotechnology, Shanghai, China), and equal amount of proteins were separated on SDS-PAGE. After being transferred to a PVDF membrane (Millipore, Germany), non- 
A

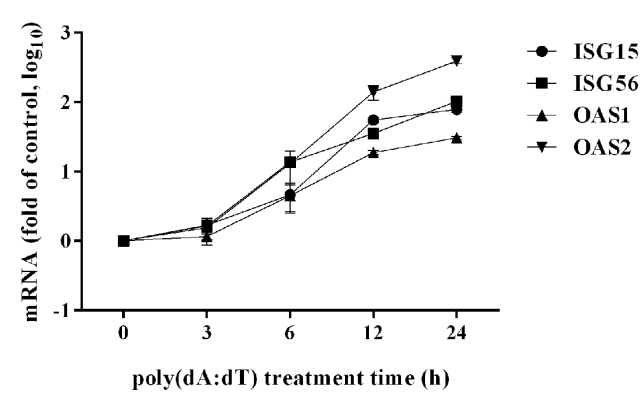

B

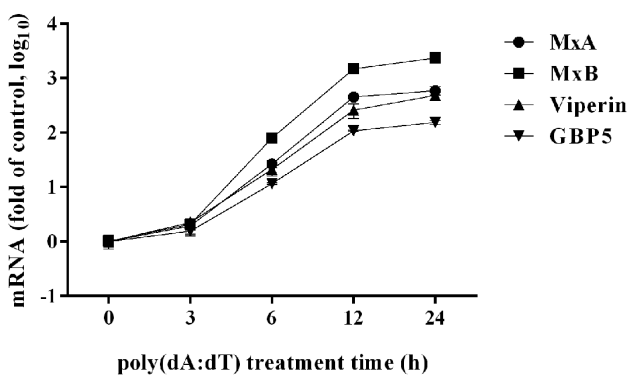

C

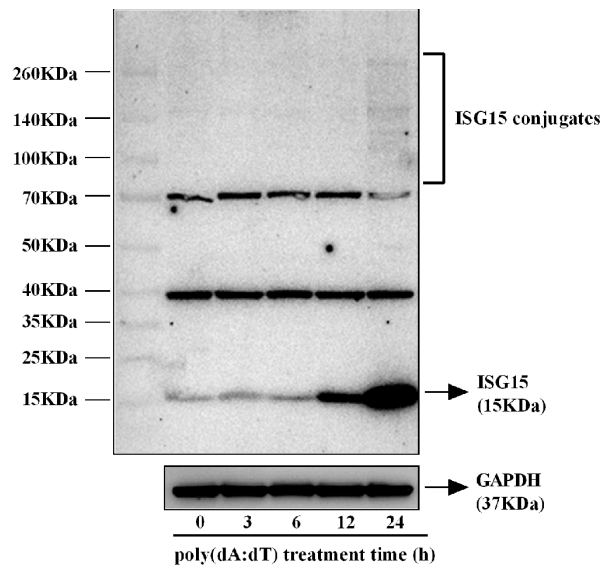

D

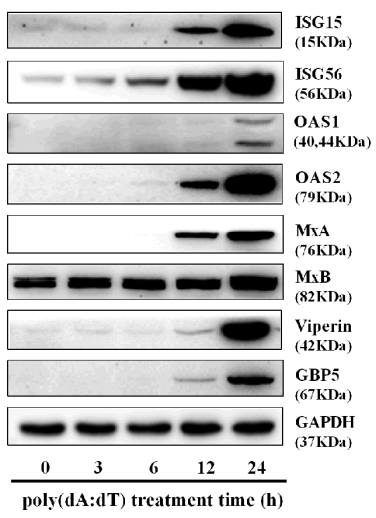

FIGURE 6 | Effect of poly(dA:dT) on ISGs expression. End1/E6E7 cells were transfected with or without poly(dA:dT) $(0.5 \mu \mathrm{g} / \mathrm{ml})$ for the indicated times. (A, B) Total cellular RNAs were isolated and subjected to the real-time PCR for ISG15, ISG56, OAS1, OAS2, MxA, MxB, viperin, and GBP5 expression. (C, D) Total cellular proteins were collected and subjected to Western blot with antibodies against ISG15 and ISG15-conjugates, ISG56, OAS1, OAS2, MxA, MxB, Viperin, GBP5, and GAPDH. Data shown represent the mean \pm SD of three independent experiments.

specific sites were blocked with $5 \%$ non-fat milk for $3 \mathrm{~h}$ prior to incubating with primary antibodies at $4^{\circ} \mathrm{C}$ overnight. The membranes were washed with TBST and further incubated with horseradish peroxidase-conjugated second antibody. Blots were developed with SuperSignal West Pico Chemiluminescent Substrate (Thermo Fisher Scientific, Waltham).

\section{ELISA}

IFN- $\beta$, IFN- $\lambda 1 / 3$, and IFN- $\lambda 2$ protein levels in cells culture supernatant were measured by ELISA kits (R\&D system Inc., $\mathrm{MH}$, USA). The assays were carried out according to the manufacturer's instruction.

\section{Statistical Analysis}

Data were presented as mean \pm SD from at least three independent experiments, and statistical significance was analyzed by Student's t-test using GraphPad Prism for Windows version 5.0 (GraphPad Software Inc., San Diego, CA). Statistical significance was defined as $P<0.05$ or $P<0.01$.

\section{RESULTS}

\section{Poly(dA:dT) Has Little Cytotoxicity Effect on End1/E6E7 Cells}

We first examined the effect of poly(dA:dT) on the viability and apoptosis of End1/E6E7 cells. As shown in Figures 1B, C, little cytotoxic and apoptosis effect was observed in End1/E6E7 cells treated with poly $(\mathrm{dA}: \mathrm{dT})$ at the dose as high as $10 \mu \mathrm{g} / \mathrm{ml}$.

\section{Poly(dA:dT) Inhibits HSV-2 Infection of End1/E6E7 Cells}

To determine the anti-HSV-2 effect of poly(dA:dT), End1/E6E7 cells were pretreated with poly $(\mathrm{dA}: \mathrm{dT})$ for $24 \mathrm{~h}$ prior to HSV-2 infection. As shown in Figures 2A, C, E, cells transfected with poly(dA:dT) had lower levels of intracellular and extracellular HSV-2 DNA/ protein than the control cells. This poly(dA:dT)-mediated HSV-2 inhibition was dose-dependent. To further determine the anti-HSV2 effect of poly(dA:dT), End1/E6E7 cells were treated with poly(dA: $\mathrm{dT}$ ) under different treatment conditions (before, simultaneously and after HSV-2 infection). As shown in Figures 2B, D, F, under all 
A

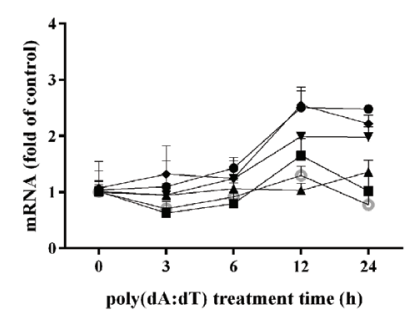

C

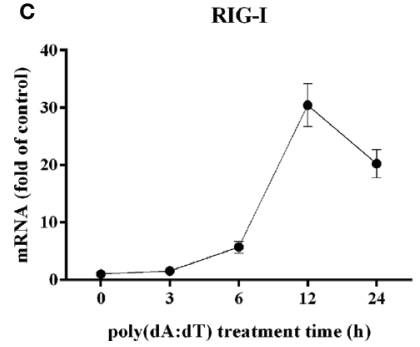

B

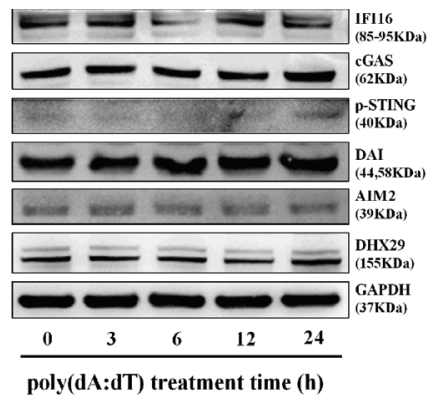

D

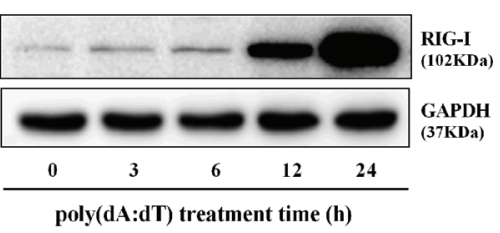

FIGURE 7 | Effect of poly(dA:dT) on the DNA sensors and RIG-I. End1/E6E7 cells were transfected with or without poly(dA:dT) $(0.5 \mu \mathrm{g} / \mathrm{ml})$ for the indicated times. (A) Total cellular RNAs were extracted and the messenger RNA (mRNA) levels of DNA sensors (IFI16, cGAS, STING, DAl, AIM2, and DHX29) were measured by the real-time PCR. (B) Total cellular proteins were collected and subjected to Western blot with the antibodies against IFI16, cGAS, p-STING, DAl, AIM2, DHX29, and GAPDH. (C) Total cellular RNAs were extracted and subjected to the real-time PCR for measuring RIG-I mRNA. (D) Total cellular proteins were collected and subjected to Western blot with the antibodies against RIG-I and GAPDH. Representative data are the mean \pm SD of three independent experiments.

A

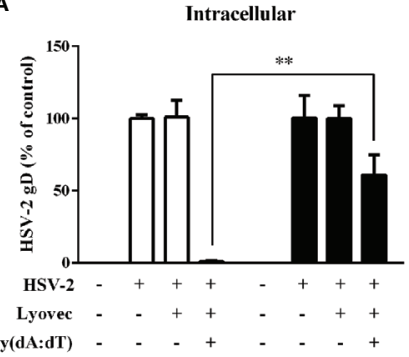

B

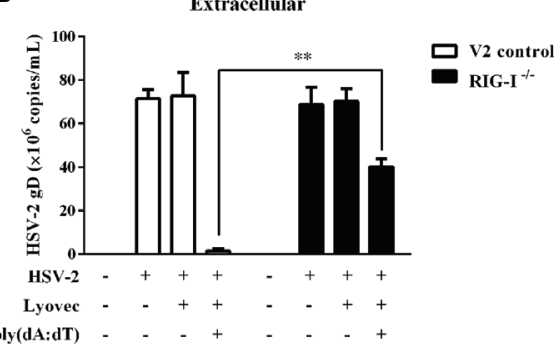

C

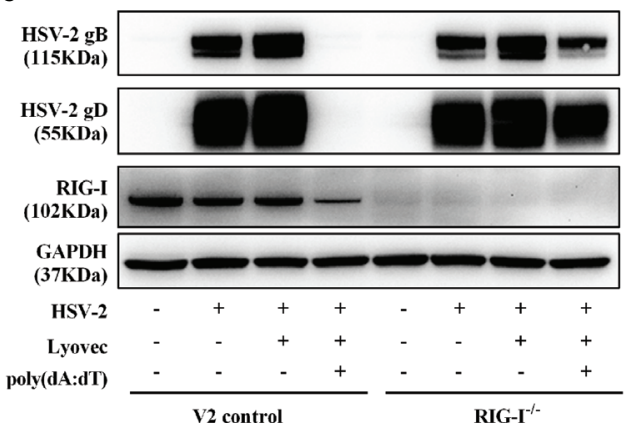

FIGURE 8 | Effect of RIG-I knockout on poly(dA:dT)-mediated HSV-2 inhibition. End1/E6E7 control cells (V2 control) and RIG-I knockout End1/E6E7 cells (RIG-1 ${ }^{-/-}$) were transfected with or without poly $(\mathrm{dA}: \mathrm{dT})(0.5 \mu \mathrm{g} / \mathrm{ml})$ for $24 \mathrm{~h}$ prior to HSV-2 infection (MOI = 0.001). (A, B) Total DNAs extracted from cells (intracellular) and culture supernatant (Extracellular) were measured by the real-time PCR for HSV-2 gD expression. (C) Total cellular proteins were collected and subjected to Western blot with antibodies against HSV-2 gB, HSV-2 gD, RIG-I, and GAPDH. The results are the mean \pm SD of three independent experiments. Asterisks indicate that the differences between the indicated groups are statistically significant $\left({ }^{\star *} P<0.01\right)$. 
A

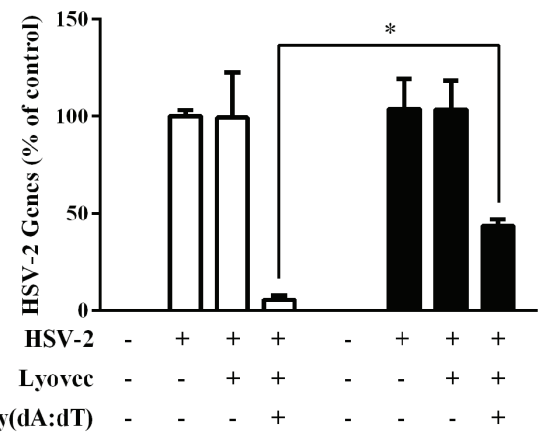

C

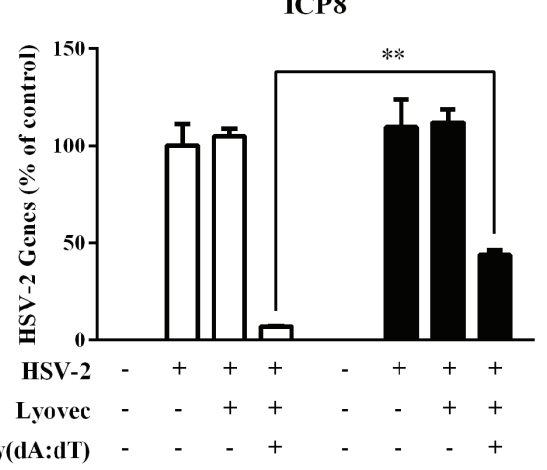

E

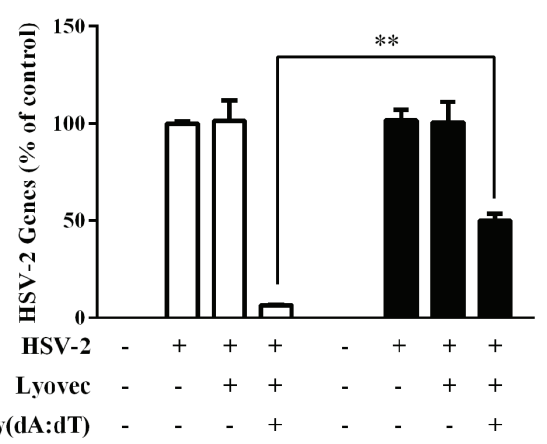

B

ICP27

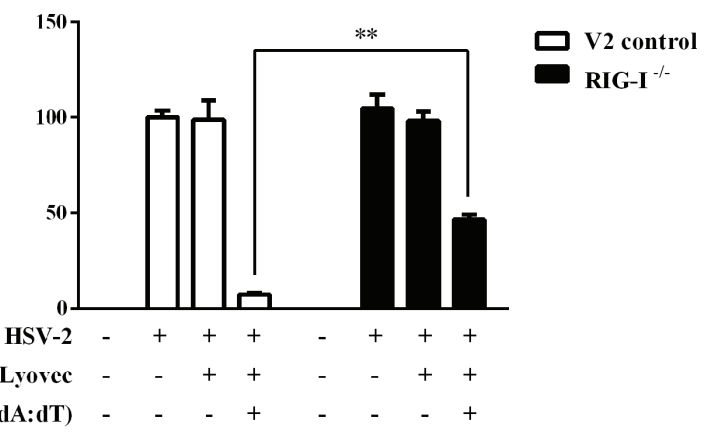

D

DNA Polymerase

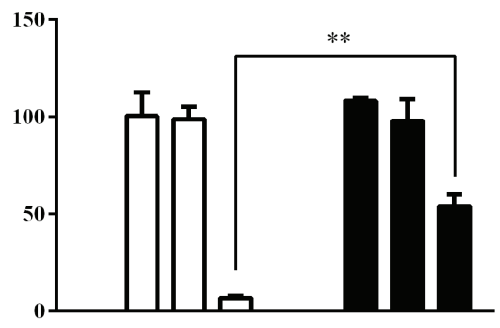

HSV-2 - + + + + + +

Lyovec - $\quad+\quad+\quad-\quad+\quad+$ $\operatorname{poly}(\mathrm{dA}: \mathrm{dT}) \quad-\quad-\quad-\quad+\quad-\quad-\quad-\quad+$

$\mathbf{F}$

HSV-2 gD

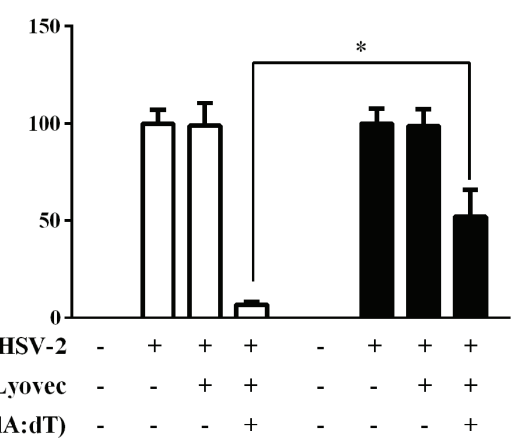

FIGURE 9 | Effect of RIG-I knockout on poly(dA:dT)-mediated inhibtion of HSV-2 gene expression. End1/E6E7 control cells (V2 control) and RIG-I knockout End1/ E6E7 cells $\left(\mathrm{RIG}--^{-/-}\right)$were transfected with or without poly $(\mathrm{dA}: \mathrm{dT})(0.5 \mu \mathrm{g} / \mathrm{ml})$ for $24 \mathrm{~h}$ prior to HSV-2 infection $(\mathrm{MOI}=0.001)$. At $24 \mathrm{~h}$ post HSV-2 infection, cellular RNAs were collected and subjected to the real-time PCR for HSV-2 immediate early genes (A, B), early genes (C, D), and late genes (E, F) expression. The results were measured as HSV-2 gene levels relative (\%) to control (without treatment, which is defined as 100\%). Data are shown as mean \pm SD for three independent experiments. Asterisks indicate that the differences between the indicated groups are statistically significant $\left({ }^{*} P<0.05,{ }^{* *} P<0.01\right)$.

the three treatment conditions, poly(dA:dT) were able to significantly suppress HSV-2 infection at both DNA and protein levels. Pretreatment of the cells with poly(dA:dT) was the most effective in HSV-2 inhibition (Figures 2B, D, F). In addition, we examined the effect of poly(dA:dT) on several key HSV-2 genes, including two immediate early genes (IE: ICP0 and ICP27), two early genes (E: ICP8 and DNA polymerase) and two late genes (L: HSV-2 gC and gD). As shown in Figure 3, poly(dA:dT) could significantly inhibit the expression of HSV-2 IE (Figures 3A, B), E (Figures 3C, D) and L (Figures 3E, F) genes in the infected cells.

\section{Poly(dA:dT) Activates the JAK/STAT Signaling Pathway}

To determine the mechanisms by which poly(dA:dT) inhibits HSV-2 infection of End1/E6E7 cells (Figures 2 and 3), we examined whether poly(dA:dT) could activate IFN-based 
A

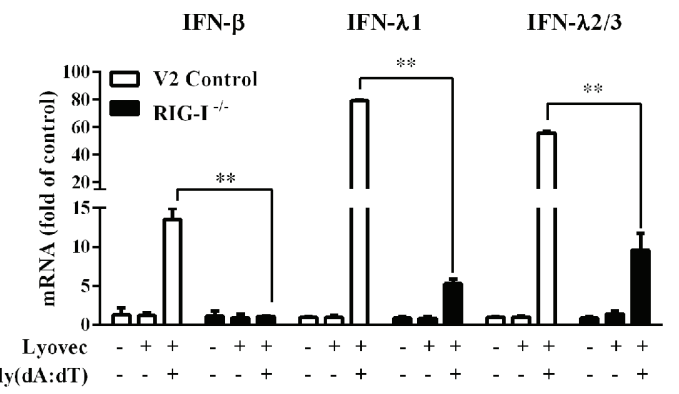

C

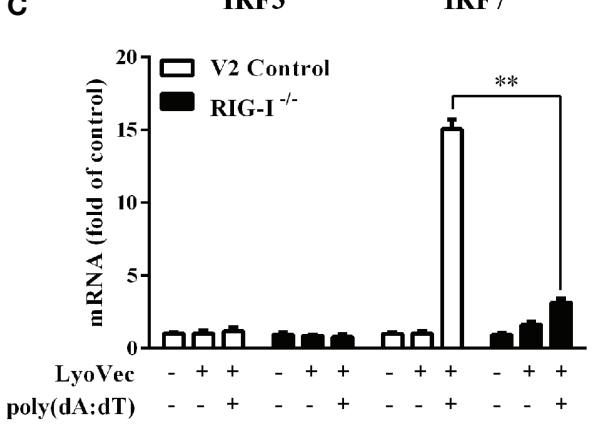

B

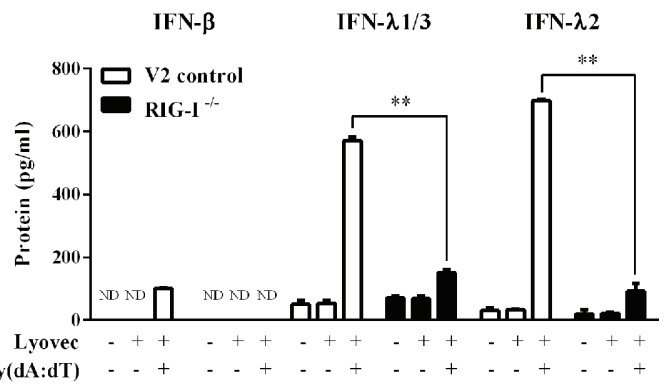

D

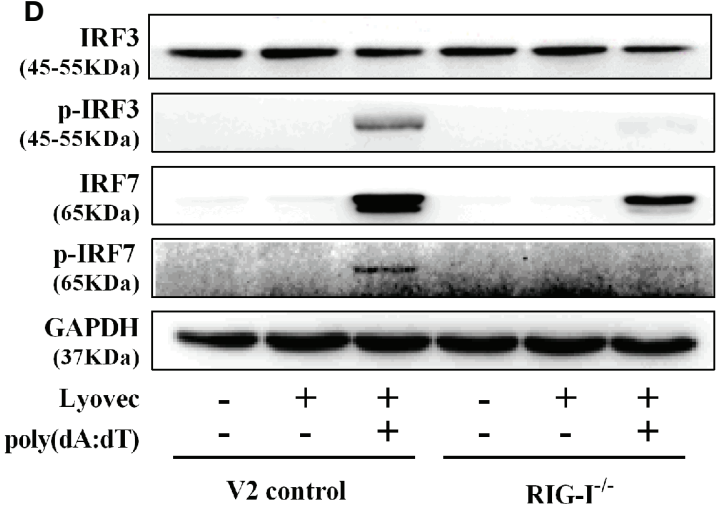

FIGURE 10 | Effect of RIG-I knockout on poly(dA:dT)-induced expression of IFNs and IRFs. End1/E6E7 control cells (V2 control) and RIG-I knockout End1/E6E7 cells $\left(\mathrm{RIG}-\mathrm{I}^{-/-}\right)$were transfected with or without poly(dA:dT) $(0.5 \mu \mathrm{g} / \mathrm{ml})$ for $12 \mathrm{~h}$. (A, C) Total cellular RNAs were extracted and subjected to the real-time PCR for IRF3, IRF7, IFN- $\beta$, IFN- $\lambda 1$, and IFN- $\lambda 2 / 3$ mRNA expression. (B) The cell-free supernatant was collected and subjected to ELISA assay to determine IFN- $\beta$, IFN- $\lambda 1 / 3$, and IFN- $\lambda 2$ protein levels. (D) Total cellular proteins were collected and subjected to Western blot with antibodies against IRF3, IRF7, p-IRF3, p-IRF7, and GAPDH. The results are the mean \pm SD of three independent experiments. Asterisks indicate that the differences between the indicated groups are statistically significant (ND, not detected, $\left.{ }^{\star \star} P<0.01\right)$.

immunity in End1/E6E7 cells. As shown in Figures 4A, B, poly $(\mathrm{dA}: \mathrm{dT})$ induced the expression of IFN- $\beta$ and IFN- $\lambda$ at both mRNA (Figure 4A) and protein (Figure 4B) levels. These effects of poly $(\mathrm{dA}: \mathrm{dT})$ on IFN- $\beta$ and IFN- $\lambda$ induction were timedependent. We next studied whether IRF3 and IRF7, the key positive regulators of the IFN signaling pathway, were involved in the IFN- $\beta$ and IFN- $\lambda$ induction by poly(dA:dT) in End1/E6E7 cells. As shown in Figure 4D, poly $(\mathrm{dA}: \mathrm{dT})$ facilitated the phosphorylation of both IRF3 and IRF7 (p-IRF3 and p-IRF7), which were positively associated with the treatment time of poly (dA:dT) in End1/E6E7 cells.

To determine whether the induction of IFN- $\beta$ and IFN- $\lambda$ is responsible for the activation of JAK/STAT signaling pathway, we analyzed the impact of poly $(\mathrm{dA}: \mathrm{dT})$ on the expression of signal transducers and activators of transcription (STATs). As shown in Figure 5, poly(dA:dT) induced the mRNA expression of STAT1, STAT2, STAT3 (Figure 5A), and protein expression of p-STAT1, p-STAT2, p-STAT3, IFN-regulated transcription factor 3 (ISGF-3)- $\gamma$ p48 in a time-dependent fashion (Figure 5B). In addition, poly(dA:dT) treatment of End1/E6E7 cells also induced the expression of ISG15, ISG56, OAS1, OAS2, MxA, $\mathrm{MxB}$, Viperin, and GBP5 at both mRNA (Figures 6A, B) and protein levels (Figures $6 \mathrm{C}, \mathbf{D}$ ).

\section{Poly(dA:dT) Induces RIG-I}

In addition to the DNA sensors $(30-32)$, RIG-I $(16,17)$ is involved in sensing cytosolic DNA. We thus examined the effect of poly(dA:dT) on RIG-I expression in End/E6E7 cells. As shown in Figures $\mathbf{7 C}$, D, poly $(\mathrm{dA}: \mathrm{dT})$ time-dependently enhanced the expression of RIG-I in the cells. In contrast, poly (dA:dT) had little effect on the expression of the key DNA sensors (IFI16, cGAS, phosphor-stimulator of IFN genes (pSTING), DAI, AIM2, and DExH-box helicase 29 (DHX29) (Figures 7A, B).

\section{RIG-I Knockout Significantly Compromises Poly(dA:dT)-Mediated HSV-2 Inhibition}

To determine whether RIG-I plays a role in poly(dA:dT)-mediated HSV-2 inhibition, we constructed RIG-I knockout End1/E6E7 cells $\left(\mathrm{RIG}_{-} \mathrm{I}^{-/-}\right.$) and End1/E6E7 V2 control cells (V2 control) through CRISPR Cas9 system (Figure 1A). As shown in Figures 8A-C, the levels of both HSV-2 DNA (Figures 8A, B) and protein (Figure 8C) in $\mathrm{RIG}^{-\mathrm{I}^{-/}}$cells were significantly higher than those in V2 control cells. In addition, we examined the impact of RIG-I knockout on poly(dA:dT)-mediated HSV-2 gene inhibition and 
observed that RIG-I ${ }^{-/-}$cells has higher levels of HSV-2 IE, E and L genes expression than V2 control cells (Figure 9). The expression level of RIG-I in HSV-2 infected cells was lower than those in uninfected cells. Especially, the expression level of RIG-I in HSV-2 infected cells which were pretreated with poly(dA:dT) was significantly lower than those in uninfected cells.

\section{RIG-I Knockout Diminishes the Effect of Poly(dA:dT) on the Activation of JAK/STAT Signaling Pathway}

To determine whether RIG-I is vital for poly(dA:dT)-mediated IFN induction, we examined the levels of IFN- $\beta$ and IFN- $\lambda$ in RIG-I knockout cells (RIG-I ${ }^{-/}$) and control cells (V2 control) transfected with poly(dA:dT). As shown in Figures 10A, B, IFN$\beta$ and IFN- $\lambda$ levels in RIG-I ${ }^{-1-}$ cells were significantly lower than those in V2 control cells. In addition, we examined the impact of RIG-I knockout on the expression of IRF3 and IRF7, the key regulators of IFNs. We observed that there was a significant decrease in the levels of p-IRF3 and p-IRF7 in RIG-I ${ }^{-/-}$cells as compared to those in V2 control cells (Figure 10D). To determine whether the suppression of IFN- $\beta$, IFN- $\lambda$, and IRFs in $\mathrm{RIG}^{-\mathrm{I}^{-/}}$cells is associated with the inhibition of JAK/STAT signaling pathway, we analyzed the effect of poly(dA:dT) on STATs expression. Figure 11 demonstrated that poly(dA:dT)mediated induction of p-STAT1, p-STAT2, and ISGF-3 $\gamma \mathrm{p} 48$ diminished in $\mathrm{RIG}^{-/-}$cells as compared to V2 control cells. In addition, $\mathrm{RIG}^{-1-}$ cells had lower expression of poly(dA:dT)stimulated ISGs (ISG15, ISG56, OAS1, OAS2, MxA, MxB, Viperin, and GBP5) than V2 control cells at both mRNA (Figures 12A, B) and protein (Figure 12C) levels.

\section{DISCUSSION}

As the first line of defense in FRT, human cervical epithelial cells are in direct contact with the virus and thus play an important role in preventing viral infections, including HSV-2. HSV-2 is a dsDNA virus which can be recognized by the cytosolic DNA sensors. There are several cytosolic dsDNA sensors involved in the host cells innate immunity against viral infections, including cGAS, whose secondary messenger cyclic GMP-AMP (cGAMP) can activate downstream sensor protein stimulator of IFN genes (STING). In addition to cGAS (33-35), AIM2, IFI16, and DAI are the cytosolic DNA receptors, activation of which could induce innate immune response to virus infections (36-39). Studies have shown that classical B form dsDNA is a potent immune stimulator when presents in the cytosol $(40,41)$. In the present study, we examined whether poly(dA:dT) has the ability to activate the intracellular innate immunity against HSV-2 infection of human cervical epithelial cells. We found that poly (dA:dT) could significantly induce the expression of IFNs/the antiviral ISGs (Figures 4 and 6) and inhibit HSV-2 replication (Figure 2). The investigation on the mechanisms for the induction of IFNs showed (Figures 4C, D) that poly(dA:dT) treatment of the cells enhanced the phosphorylation of IRF3 and

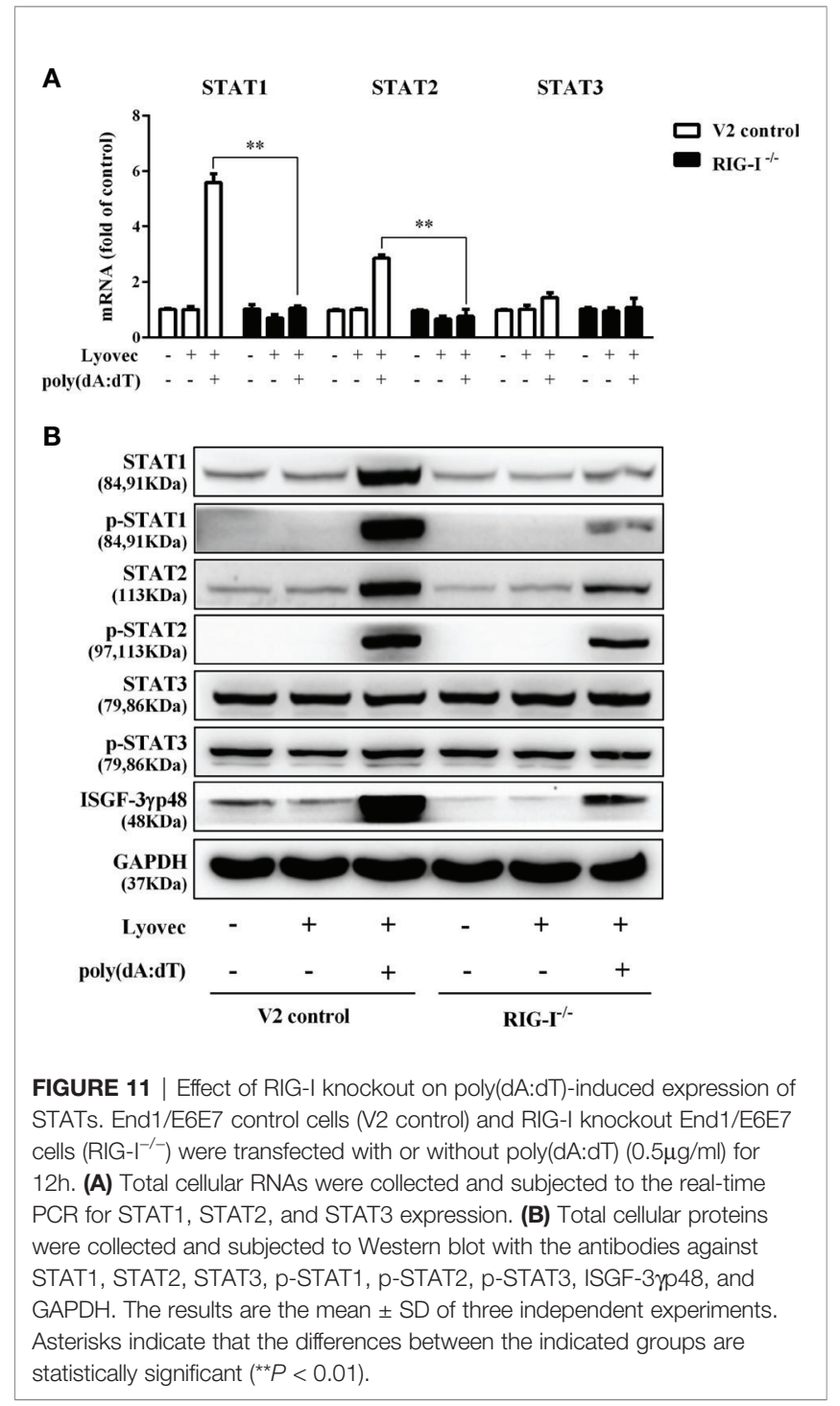

IRF7, the key and positive regulators of IFNs during viral infections (42). IRF3 and IRF7 phosphorylation is a crucial step in activating the IFNs-mediated antiviral immunity (43). During viral infections, IRF3 is important in the early phase of inducing the transcription of IFN- $\alpha$ and IFN- $\beta$, which results in the IRF7 activation. Both IFN- $\beta$, IFN- $\lambda 1$ gene expression is regulated by virus-activated IRF3 and IRF7, whereas IFN- $\lambda 2 / 3$ gene expression is mainly controlled by IRF7 (44).

In addition to the positive impact on the IRFs, poly(dA:dT) could also activate the JAK/STAT signaling pathway that is vital for IFN-mediated innate immune response. We observed that poly(dA:dT) not only enhanced the expression of STAT1, STAT2, and STAT3 (Figure 5A) but also facilitate the phosphorylation of STAT1, STAT2, STAT3, and ISGF-3 $\gamma$ p48 (Figure 5B). Several studies (45-47) have shown that comparing with STATs 1 and 2, STAT3 is an acute phase response factor with a transient activation. Therefore, it is likely that activation duration of STAT3 is shorter than that of STAT1 and STAT2. 


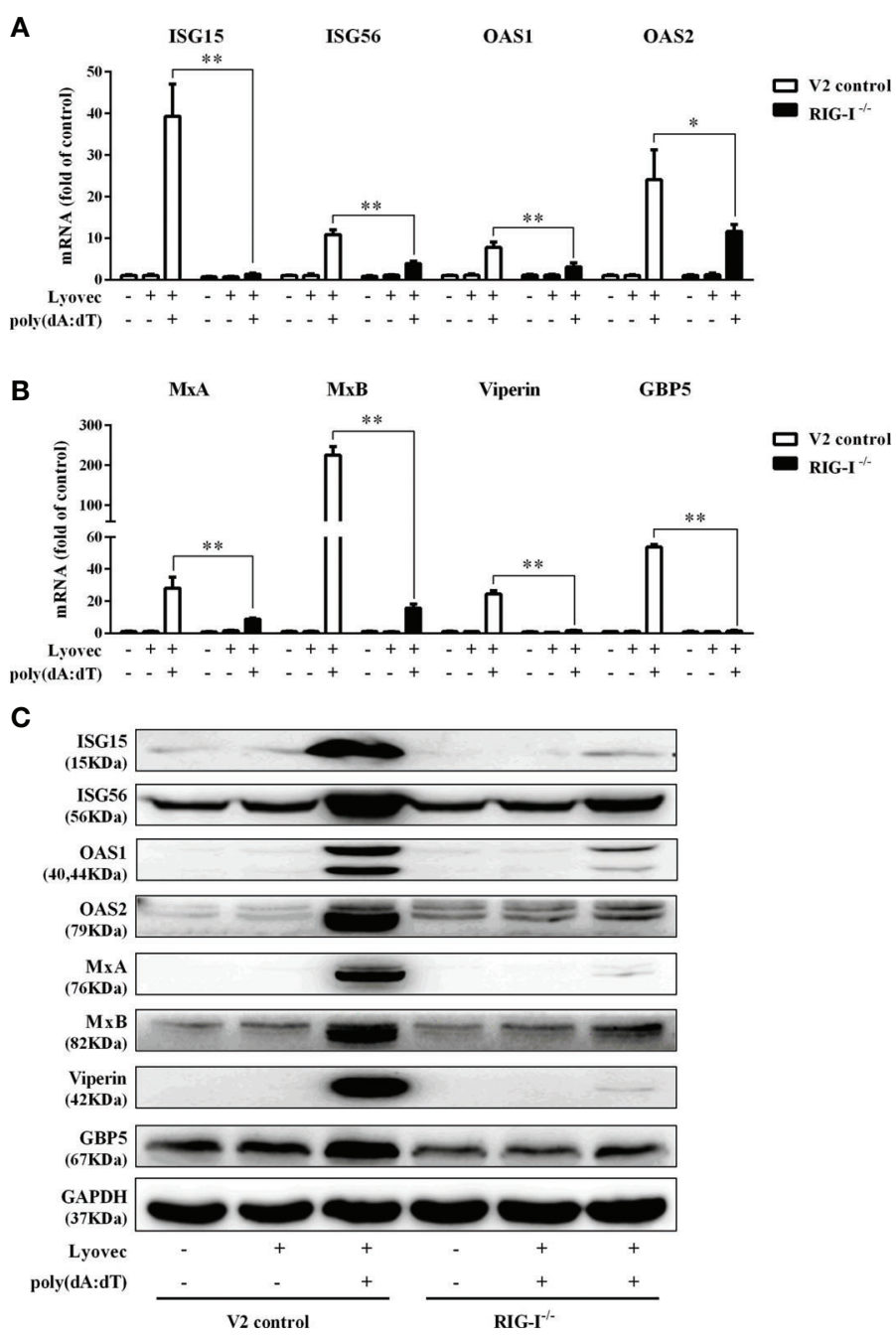

FIGURE 12 | Effect of RIG-I knockout on poly(dA:dT)-induced ISGs expression. (A, B) End1/E6E7 control cells (V2 control) and RIG-I knockout End1/E6E7 cells $\left(\mathrm{RIG}-\mathrm{I}^{-/-}\right)$were transfected with or without poly $(\mathrm{dA}: \mathrm{dT})(0.5 \mu \mathrm{g} / \mathrm{ml})$ for $12 \mathrm{~h}$. Total cellular RNAs were extracted and subjected to the real-time PCR for ISG15, ISG56,

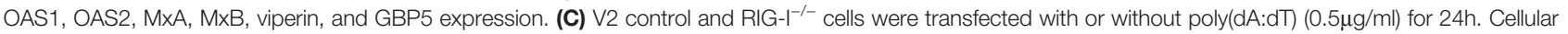
proteins were collected and subjected to Western blot with the antibodies against ISG15, ISG56, OAS1, OAS2, MxA, MxB, viperin, GBP5, and GAPDH, respectively. The results are the mean \pm SD of three independent experiments. Asterisks indicate that the differences between the indicated groups are statistically significant $\left({ }^{\star} P<0.05,{ }^{\star \star} P<0.01\right)$.

Furthermore, poly(dA:dT) treatment induced the expression of several key antiviral ISGs (Figure 6), including ISG15, ISG56, OAS1, OAS2, MxA, MxB, viperin, and GBP5, some of which are known to have the ability to inhibit HSV-2 infection. For example, OAS1 can directly inhibit HSV-2 proliferation (48), $\mathrm{MxB}$ interferes with viral replication through blocking the uncoating of viral DNA from the incoming viral capsid (49), ISG15 and ISG15-conjugates have multiple antiviral functions including inhibition of virus release and replication $(50,51)$. Therefore, the induction of these anti-HSV-2 ISGs provides a sound mechanism for poly(dA:dT)-mediated HSV-2 inhibition.

To determine the initial recognition molecule(s) for the poly (dA:dT) action on HSV-2 inhibition and IFN/ISGs induction, we first examined the effect of poly $(\mathrm{dA}: \mathrm{dT})$ on the expression of the DNA sensors. We found that poly(dA:dT) had little effect on the expression of the DNA sensors at both mRNA and protein levels (Figures 7A, B). In addition, we failed to identify a specific DNA sensor that plays a major role in poly(dA:dT)-mediated IFN/ISG induction (data not shown). In contrast, poly(dA:dT) could significantly induce the RIG-I expression in the cells (Figures 7C, D). Importantly, the vital role of RIG-I in the poly(dA:dT) actions was shown in the experiments using $\mathrm{RIG}_{-} \mathrm{I}^{-/}$and the parental control cells (Figure 1A). We observed that while poly (dA:dT) could significantly inhibit HSV-2 replication in the parental control cells, it had little effect on HSV-2 infectivity in $\mathrm{RIG}^{-1-}$ cells (Figures 8 and 9 ). In addition, $\mathrm{RIG}^{-\mathrm{I}^{-1}}$ cells 
lacked the effective response to poly $(\mathrm{dA}: \mathrm{dT})$ stimulation and expressed significantly lower levels of IFN- $\beta$ and IFN- $\lambda$, p-IRF3 and p-IRF7 than the control cells (Figure 10). Similarly, the expression of p-STAT1, p-STAT2, ISGF-3 $\gamma$ p48, and the antiviral ISGs was lower in $\mathrm{RIG}^{-1-}$ cells as compared with that in the control cells (Figures 11 and 12). Finally, the important role of RIG-I in the intracellular innate immunity against HSV-2 was also supported by the observation that RIG-I levels in HSV-2infected cells were lower than those in uninfected cells, particularly in the cells infected and transfected with poly(dA: $\mathrm{dT}$ ). The decreased expression of RIG-I in the infected cells is likely due to the negative effects of HSV-2 on the intracellular antiviral innate immunity, which is one of the strategies for the virus to escape the host cell immune response. These combined observations indicate that RIG-I is indeed a necessary and key sensor for poly(dA:dT)-mediated activation of IFN/STAT signaling pathways and HSV-2 inhibition. Therefore, it is possible that the interaction of poly(dA:dT) with RIG-I through RNA polymerase ( $\mathrm{Pol}$ ) III is crucial in initiating intracellular anti-HSV-2 innate immunity (Figure 13). Chiu et al. (17) reported that poly (dA-dT) serves as a template for the de novo synthesis of poly(A-U) RNA by DNA-dependent RNA Pol III. They showed that Pol-III is responsible for the synthesis of the RNA from poly(dA-dT), which binds directly to RIG-I. Cheng et al. also demonstrated that RIG-I is essential for B form (AT-rich) dsDNA signaling pathway as poly $(\mathrm{dA}-\mathrm{dT})$ is converted by RNA Pol III of the host cell into a 5' triphosphate RNA intermediate, which can be recognized by RIG-I (52).

Collectively, our study for the first time has demonstrated that the activation of the RIG-I by poly(dA:dT) could effectively inhibit HSV-2 infection of human cervical epithelial cells. While the precise cellular and molecular mechanisms for poly (dA:dT)-mediated HSV-2 inhibition remain to be determined, the induction of IFNs and the multiple antiviral ISGs should be largely responsible for much of poly(dA:dT)-mediated antiHSV-2 activity. These findings are clinically significant as they indicate that activating the intracellular innate immunity by poly (dA:dT) has potential for the prevention and treatment of HSV-2 infection. However, future ex vivo and in vivo investigations in animal models and clinical studies are necessary in order to determine whether poly(dA:dT) is effective in activating FRT innate immunity and beneficial for protecting human cervical epithelial cells from HSV-2 infection. These future studies will be crucial for the design and development of AT-rich dsDNA-based intervention strategies to control HSV-2 mucosal transmission in FRT.

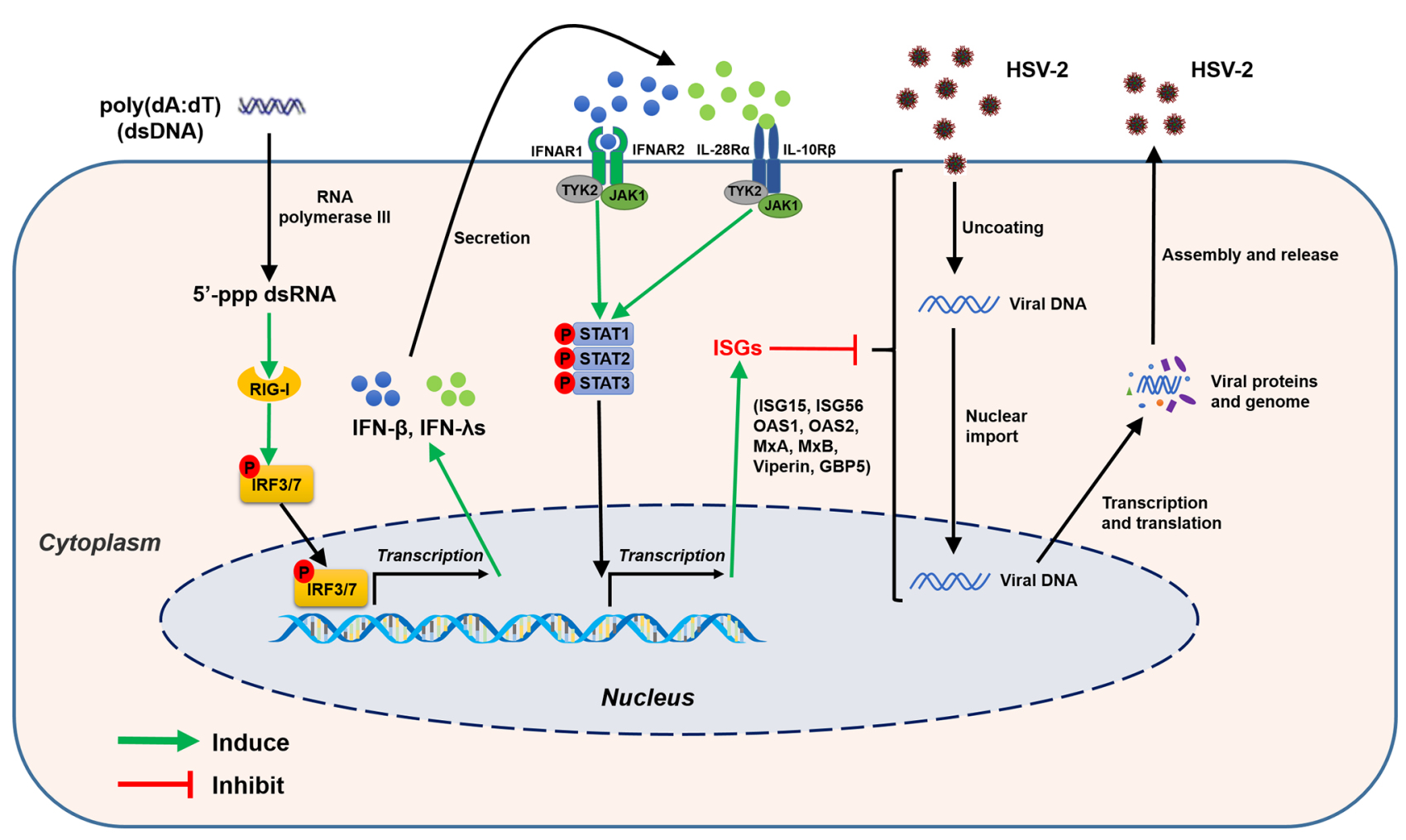

FIGURE 13 | Schematic diagram of mechanisms for poly(dA:dT)-mediated HSV-2 inhibition in human cervical epithelial cells. Poly(dA:dT) can be recognized by RNA polymerase III which then converts DNA into 5'-ppp RNA, the ligand for RIG-I. The activation of RIG-I facilitates the phosphorylation and translocation of IRF3 and IRF7, resulting in the production of IFNs. The released IFNs bind to their corresponding receptors on the cell surface, and trigger JAK/STAT signaling pathway, facilitating STATs phosphorylation and inducing the antiviral ISGs (ISG15, ISG56, OAS1, OAS2, MxA, MxB, viperin, GBP5) which have the ability to block or inhibit HSV-2 at different steps of replication cycle. 


\section{DATA AVAILABILITY STATEMENT}

The raw data supporting the conclusions of this article will be made available by the authors, without undue reservation.

\section{AUTHOR CONTRIBUTIONS}

D-DS and F-ZM performed most experiments and analyzed the data. YL, X-QX, XW, and W-HH helped with some experiments. D-DS, F-ZM, W-ZH, and WH wrote the manuscript. D-DS,

\section{REFERENCES}

1. Looker KJ, Magaret AS, May MT, Turner KM, Vickerman P, Gottlieb SL, et al. Global and Regional Estimates of Prevalent and Incident Herpes Simplex Virus Type 1 Infections in 2012. PloS One (2015) 10(10):e0140765. doi: 10.1371/journal.pone.0140765

2. Freeman EE, Weiss HA, Glynn JR, Cross PL, Whitworth JA, Hayes RJ. Herpes simplex virus 2 infection increases HIV acquisition in men and women: systematic review and meta-analysis of longitudinal studies. Aids (2006) 20 (1):73-83. doi: 10.1097/01.aids.0000198081.09337.a7

3. Gray RH, Wawer MJ, Brookmeyer R, Sewankambo NK, Serwadda D, Wabwire-Mangen F, et al. Probability of HIV-1 transmission per coital act in monogamous, heterosexual, HIV-1-discordant couples in Rakai, Uganda. Lancet (2001) 357(9263):1149-53. doi: 10.1016/S0140-6736(00)04331-2

4. Schacker T, Zeh J, Hu HL, Hill E, Corey L. Frequency of symptomatic and asymptomatic herpes simplex virus type 2 reactivations among human immunodeficiency virus-infected men. J Infect Dis (1998) 178(6):1616-22. doi: $10.1086 / 314486$

5. Augenbraun M, Feldman J, Chirgwin K, Zenilman J, Clarke L, DeHovitz J, et al. Increased genital shedding of herpes simplex virus type 2 in HIVseropositive women. Ann Intern Med (1995) 123(11):845-7. doi: 10.7326/ 0003-4819-123-11-199512010-00006

6. Schiffer JT, Gottlieb SL. Biologic interactions between HSV-2 and HIV-1 and possible implications for HSV vaccine development. Vaccine (2019) 37 (50):7363-71. doi: 10.1016/j.vaccine.2017.09.044

7. Looker KJ, Elmes JAR, Gottlieb SL, Schiffer JT, Vickerman P, Turner KME, et al. Effect of HSV-2 infection on subsequent HIV acquisition: an updated systematic review and meta-analysis. Lancet Infect Dis (2017) 17(12):1303-16. doi: 10.1016/S1473-3099(17)30405-X

8. Wira CR, Grant-Tschudy KS, Crane-Godreau MA. Epithelial cells in the female reproductive tract: a central role as sentinels of immune protection. Am J Reprod Immunol (2005) 53(2):65-76. doi: 10.1111/j.16000897.2004.00248.x

9. Blaskewicz CD, Pudney J, Anderson DJ. Structure and function of intercellular junctions in human cervical and vaginal mucosal epithelia. Biol Reprod (2011) 85(1):97-104. doi: 10.1095/biolreprod.110.090423

10. Zhao X, Deak E, Soderberg K, Linehan M, Spezzano D, Zhu J, et al. Vaginal submucosal dendritic cells, but not Langerhans cells, induce protective Th1 responses to herpes simplex virus-2. J Exp Med (2003) 197(2):153-62. doi: 10.1084/jem.20021109

11. MacDonald EM, Savoy A, Gillgrass A, Fernandez S, Smieja M, Rosenthal KL, et al. Susceptibility of human female primary genital epithelial cells to herpes simplex virus, type-2 and the effect of TLR3 ligand and sex hormones on infection. Biol Reprod (2007) 77(6):1049-59. doi: 10.1095/biolreprod.107.063933

12. Zhou L, Li JL, Zhou Y, Liu JB, Zhuang K, Gao JF, et al. Induction of interferonlambda contributes to TLR3 and RIG-I activation-mediated inhibition of herpes simplex virus type 2 replication in human cervical epithelial cells. $\mathrm{Mol}$ Hum Reprod (2015) 21(12):917-29. doi: 10.1093/molehr/gav058

13. Xu XQ, Liu Y, Zhang B, Liu H, Shao DD, Liu JB, et al. IL-22 suppresses HSV-2 replication in human cervical epithelial cells. Cytokine (2019) 123:154776. doi: 10.1016/j.cyto.2019.154776
F-ZM, W-ZH, and WH reviewed and revised the manuscript. All authors contributed to the article and approved the submitted version.

\section{ACKNOWLEDGMENTS}

We thank Qinxue Hu (State Key Laboratory of Virology, Wuhan Institute of Virology, Chinese Academy of Sciences) for providing the HSV-2 G strain.

14. Liu Y, Xu X-Q, Zhang B, Gu J, Meng F-Z, Liu H, et al. BowmanBirk Inhibitor Suppresses Herpes Simplex Virus Type 2Infection of Human Cervical Epithelial Cells. Viruses (2018) 10(10):557. doi: 10.3390/v10100557

15. Xu XQ, Guo L, Wang X, Liu Y, Liu H, Zhou RH, et al. Human Cervical Epithelial Cells Release Antiviral Factors and Inhibit HIV Replication in Macrophages. J Innate Immun (2019) 11(1):29-40. doi: 10.1159/000490586

16. Ablasser A, Bauernfeind F, Hartmann G, Latz E, Fitzgerald KA, Hornung V. RIG-I-dependent sensing of poly(dA:dT) through the induction of an RNA polymerase III-transcribed RNA intermediate. Nat Immunol (2009) 10 (10):1065-72. doi: 10.1038/ni.1779

17. Chiu YH, Macmillan JB, Chen ZJ. RNA polymerase III detects cytosolic DNA and induces type I interferons through the RIG-I pathway. Cell (2009) 138 (3):576-91. doi: 10.1016/j.cell.2009.06.015

18. Bauernfeind F, Ablasser A, Kim S, Bartok E, Hornung V. An unexpected role for RNA in the recognition of DNA by the innate immune system. RNA Biol (2010) 7(2):151-7. doi: 10.4161/rna.7.2.11058

19. Paz S, Sun Q, Nakhaei P, Romieu-Mourez R, Goubau D, Julkunen I, et al. Induction of IRF-3 and IRF-7 phosphorylation following activation ofthe RIG-I pathway. Cell Mol Biol (Noisy-le-Grand France) (2006) 52:17-28. doi: 10.1170/T694

20. Sato S, Li K, Kameyama T, Hayashi T, Ishida Y, Murakami S, et al. The RNA Sensor RIG-I Dually Functions as an Innate Sensor and Direct Antiviral Factor for Hepatitis B Virus. Immunity (2015) 42(1):123-32. doi: 10.1016/ j.immuni.2014.12.016

21. Hemann EA, Gale M, Savan R. Interferon Lambda Genetics and Biology in Regulation of Viral Control. Front Immunol (2017) 8(1707). doi: 10.3389/ fimmu.2017.01707

22. Hirata Y, Broquet AH, Menchen L, Menchen L, Kagnoff MF. Activation of innate immune defense mechanisms by signaling through RIG-I/IPS-1 in intestinal epithelial cells. J Immunol (2007) 179(8):5425-32. doi: 10.4049/ jimmunol.179.8.5425

23. Chauveau E, Doceul V, Lara E, Adam M, Breard E, Sailleau C, et al. Sensing and control of bluetongue virus infection in epithelial cells via RIG-I and MDA5 helicases. J Virol (2012) 86(21):11789-99. doi: 10.1128/ JVI.00430-12

24. Le Goffic R, Pothlichet J, Vitour D, Fujita T, Meurs E, Chignard M, et al. Cutting Edge: Influenza A virus activates TLR3-dependent inflammatory and RIG-I-dependent antiviral responses in human lung epithelial cells. J Immunol (2007) 178(6):3368-72. doi: 10.4049/jimmunol.178.6.3368

25. Fichorova RN, Rheinwald JG, Anderson DJ. Generation of papillomavirusimmortalized cell lines from normal human ectocervical, endocervical, and vaginal epithelium that maintain expression of tissue-specific differentiation proteins. Biol Reprod (1997) 57(4):847-55. doi: 10.1095/biolreprod57.4.847

26. Pandit H, Kale K, Yamamoto H, Thakur G, Rokade S, Chakraborty P, et al. Surfactant Protein D Reverses the Gene Signature of Transepithelial HIV-1 Passage and Restricts the Viral Transfer Across the Vaginal Barrier. Front Immunol (2019) 10:264. doi: 10.3389/fimmu.2019.00264

27. Zadora PK, Chumduri C, Imami K, Berger H, Mi Y, Selbach M, et al. Integrated Phosphoproteome and Transcriptome Analysis Reveals Chlamydia-Induced Epithelial-to-Mesenchymal Transition in Host Cells. Cell Rep (2019) 26(5):1286-302.e8. doi: 10.1016/j.celrep.2019.01.006 
28. Shalem O, Sanjana NE, Hartenian E, Shi X, Scott DA, Mikkelson T, et al. Genome-scale CRISPR-Cas9 knockout screening in human cells. Science (2014) 343(6166):84-7. doi: 10.1126/science.1247005

29. Sanjana NE, Shalem O, Zhang F. Improved vectors and genome-wide libraries for CRISPR screening. Nat Methods (2014) 11(8):783-4. doi: 10.1038/ nmeth.3047

30. Unterholzner L. The interferon response to intracellular DNA: why so many receptors? Immunobiology (2013) 218(11):1312-21. doi: 10.1016/ j.imbio.2013.07.007

31. Zhang Z, Yuan B, Bao M, Lu N, Kim T, Liu YJ. The helicase DDX41 senses intracellular DNA mediated by the adaptor STING in dendritic cells. Nat Immunol (2011) 12(10):959-65. doi: 10.1038/ni.2091

32. Wu J, Sun L, Chen X, Du F, Shi H, Chen C, et al. Cyclic GMP-AMP is an endogenous second messenger in innate immune signaling by cytosolic DNA. Science (2013) 339(6121):826-30. doi: 10.1126/science.1229963

33. Ablasser A, Chen ZJ. cGAS in action: Expanding roles in immunity andinflammation. Science (2019) 363(6431):eaat8657. doi: 10.1126/science. aat8657

34. Ablasser A, Goldeck M, Cavlar T, Deimling T, Witte G, Röhl I, et al. cGAS produces a $2^{\prime}-5^{\prime}$-linked cyclic dinucleotide second messenger that activates STING. Nature (2013) 498(7454):380-4. doi: 10.1038/nature12306

35. Wu J, Sun L, Chen X, Du F, Shi H, Chen C, et al. Cyclic GMP-AMP Is an Endogenous Second Messenger in Innate Immune Signaling by Cytosolic DNA. Science (2013) 339(6121):826. doi: 10.1126/science.1229963

36. Takaoka A, Wang Z, Choi MK, Yanai H, Negishi H, Ban T, et al. DAI (DLM$1 / \mathrm{ZBP} 1)$ is a cytosolic DNA sensor and an activator of innate immune response. Nature (2007) 448(7152):501-5. doi: 10.1038/nature06013

37. Eriksson K, Svensson A, Hait AS, Schluter K, Tunback P, et al. Cutting Edge: Genetic Association between IFI16 Single NucleotidePolymorphisms and Resistance to Genital Herpes Correlates with IFI16 Expression Levels and HSV-2-Induced IFN-beta Expression. J Immunol (2017) 199(8):2613-7. doi: 10.4049/jimmunol.1700385

38. Kerur N, Veettil MV, Sharma-Walia N, Bottero V, Sadagopan S, Otageri P, et al. IFI16 acts as a nuclear pathogen sensor to induce the inflammasome in response to Kaposi Sarcoma-associated herpesvirus infection. Cell Host Microbe (2011) 9(5):363-75. doi: 10.1016/j.chom.2011.04.008

39. Monroe KM, Yang Z, Johnson JR, Geng X, Doitsh G, Krogan NJ, et al. IFI16 DNA Sensor Is Required for Death of Lymphoid CD4 T Cells Abortively Infected with HIV. Science (2014) 343(6169):428. doi: 10.1126/ science. 1243640

40. Stetson DB, Medzhitov R. Recognition of Cytosolic DNA Activates an IRF3Dependent Innate Immune Response. Immunity (2006) 24(1):93-103. doi: 10.1016/j.immuni.2005.12.003

41. Ishii KJ, Coban C, Kato H, Takahashi K, Torii Y, Takeshita F, et al. A Toll-like receptor-independent antiviral response induced by double-stranded B-form DNA. Nat Immunol (2006) 7(1):40-8. doi: 10.1038/ni1282
42. Lazear HM, Nice TJ, Diamond MS. Interferon-lambda: Immune Functions at Barrier Surfaces and Beyond. Immunity (2015) 43(1):15-28. doi: 10.1016/ j.immuni.2015.07.001

43. Honda K, Takaoka A, Taniguchi T. Type I interferon [corrected] gene induction by the interferon regulatory factor family of transcription factors. Immunity (2006) 25(3):349-60. doi: 10.1016/j.immuni.2006.08.009

44. Osterlund PI, Pietila TE, Veckman V, Kotenko SV, Julkunen I. IFN regulatory factor family members differentially regulate the expression of type III IFN (IFN-lambda) genes. J Immunol (2007) 179(6):3434-42. doi: 10.4049/ jimmunol.179.6.3434

45. Raz R, Durbin JE, Levy DE. Acute phase response factor and additional members of the interferon-stimulated gene factor 3 family integrate diverse signals from cytokines, interferons, and growth factors. J Biol Chem (1994) 269(39):24391-5. doi: 10.1016/S0021-9258(19)51096-1

46. Akira S. IL-6-regulated transcription factors. Int J Biochem Cell Biol (1997) 29 (12):1401-18. doi: 10.1016/S1357-2725(97)00063-0

47. Tomic J, Lichty B, Spaner DE. Aberrant interferon-signaling is associated with aggressive chronic lymphocytic leukemia. Blood (2011) 117(9):2668-80. doi: 10.1182/blood-2010-05-285999

48. Kristiansen H, Scherer CA, McVean M, Iadonato SP, Vends S, Thavachelvam K, et al. Extracellular 2'-5' oligoadenylate synthetase stimulates RNase Lindependent antiviral activity: a novel mechanism of virus-induced innate immunity. J Virol (2010) 84(22):11898-904. doi: 10.1128/JVI.01003-10

49. Crameri M, Bauer M, Caduff N, Walker R, Steiner F, Franzoso FD, et al. MxB is an interferon-induced restriction factor of human herpesviruses. Nat Commun (2018) 9(1):1980-0. doi: 10.1038/s41467-018-04379-2

50. Morales DJ, Lenschow DJ. The antiviral activities of ISG15. J Mol Biol (2013) 425(24):4995-5008. doi: 10.1016/j.jmb.2013.09.041

51. Perng Y-C, Lenschow DJ. ISG15 in antiviral immunity and beyond. Nat Rev Microbiol (2018) 16(7):423-39. doi: 10.1038/s41579-018-0020-5

52. Cheng G, Zhong J, Chung J, Chisari FV. Double-stranded DNA and doublestranded RNA induce a common antiviral signaling pathway in human cells. Proc Natl Acad Sci (2007) 104(21):9035. doi: 10.1073/pnas. 0703285104

Conflict of Interest: The authors declare that the research was conducted in the absence of any commercial or financial relationships that could be construed as a potential conflict of interest.

Copyright (c) 2021 Shao, Meng, Liu, Xu, Wang, Hu, Hou and Ho. This is an openaccess article distributed under the terms of the Creative Commons Attribution License (CC BY). The use, distribution or reproduction in other forums is permitted, provided the original author(s) and the copyright owner(s) are credited and that the original publication in this journal is cited, in accordance with accepted academic practice. No use, distribution or reproduction is permitted which does not comply with these terms. 